\title{
Guidelines for volcano-observatory operations during crises: recommendations from the 2019 volcano observatory best practices meeting
}

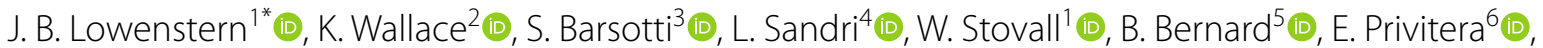 \\ J.-C. Komorowski ${ }^{7}$, N. Fournier ${ }^{8}$ (D) C. Balagizi ${ }^{9}$ and E. Garaebiti ${ }^{10}$ (i)
}

\begin{abstract}
In November 2019, the fourth Volcano Observatory Best Practices workshop was held in Mexico City as a series of talks, discussions, and panels. Volcanologists from around the world offered suggestions for ways to optimize volcanoobservatory crisis operations. By crisis, we mean unrest that may or may not lead to eruption, the eruption itself, or its aftermath, all of which require analysis and communications by the observatory. During a crisis, the priority of the observatory should be to acquire, process, analyze, and interpret data in a timely manner. A primary goal is to communicate effectively with the authorities in charge of civil protection. Crisis operations should rely upon exhaustive planning in the years prior to any actual unrest or eruptions. Ideally, nearly everything that observatories do during a crisis should be envisioned, prepared, and practiced prior to the actual event. Pre-existing agreements and exercises with academic and government collaborators will minimize confusion about roles and responsibilities. In the situation where planning is unfinished, observatories should prioritize close ties and communications with the land and civildefense authorities near the most threatening volcanoes.

To a large extent, volcanic crises become social crises, and any volcano observatory should have a communication strategy, a lead communicator, regular status updates, and a network of colleagues outside the observatory who can provide similar messaging to a public that desires consistent and authoritative information. Checklists permit tired observatory staff to fulfill their duties without forgetting key communications, data streams, or protocols that need regular fulfilment (Bretton et al. Volcanic Unrest. Advances in Volcanology, 2018; Newhall et al. Bull Volcanol 64:3-20, 2020). Observatory leaders need to manage staff workload to prevent exhaustion and ensure that expertise is available as needed. Event trees and regular group discussions encourage multi-disciplinary thinking, consideration of disparate viewpoints, and documentation of all group decisions and consensus. Though regulations, roles and responsibilities differ around the world, scientists can justify their actions in the wake of an eruption if they document their work, are thoughtful and conscientious in their deliberations, and carry out protocols and procedures developed prior to volcanic unrest. This paper also contains six case studies of volcanic eruptions or observatory actions that illustrate some of the topics discussed herein. Specifically, we discuss Ambae (Vanuatu) in 2017-2018, Kïlauea (USA) in 2018, Etna (Italy) in 2018, Bárðarbunga
\end{abstract}

\footnotetext{
*Correspondence: jlwnstrn@usgs.gov

${ }^{1}$ U.S. Geological Survey, Volcano Science Center, Vancouver, WA, USA

Full list of author information is available at the end of the article
} permits use, sharing, adaptation, distribution and reproduction in any medium or format, as long as you give appropriate credit to the original author(s) and the source, provide a link to the Creative Commons licence, and indicate if changes were made. The images or other third party material in this article are included in the article's Creative Commons licence, unless indicated otherwise in a credit line to the material. If material is not included in the article's Creative Commons licence and your intended use is not permitted by statutory regulation or exceeds the permitted use, you will need to obtain permission directly from the copyright holder. To view a copy of this licence, visit http://creativecommons.org/licenses/by/4.0/. The Creative Commons Public Domain Dedication waiver (http://creativeco mmons.org/publicdomain/zero/1.0/) applies to the data made available in this article, unless otherwise stated in a credit line to the data. 
(Iceland) in 2014, Cotopaxi (Ecuador) in 2015, and global data sharing to prepare for eruptions at Nyiragongo (Democratic Republic of Congo). A Spanish-language version of this manuscript is provided as Additional file 1.

Keywords: Volcano, Observatory, Crisis, Eruption, Protocols, Communications, Alarms, Operations, Practices

\section{Introduction}

Crisis operations represent the ultimate test of a volcano observatory, challenging its ability to fulfill its goal of accurate and timely warnings to help protect populations from volcanic eruptions. During volcanic crises, the observatory is typically required to operate continuously, with little opportunity for the staff to rest and maximal testing of plans, protocols, and resources. With passage of the Sendai Framework for Disaster Risk Reduction (UNDRR 2015), volcano observatories clearly fit within the global priorities of understanding and managing disaster risk, investing in resilience and enhancing disaster preparedness. The volcanology community has a clear role in this effort by strengthening volcano observatories and instituting best practices where feasible.

During 5 days in late November 2019, the fourth Volcano Observatory Best Practices (VOBP) meeting was held in Mexico City (Figs. 1, and 2) and hosted by CENAPRED (Centro Nacional de Prevención de Desastres). The meeting followed three earlier VOBP meetings held over the previous 8 years (Pallister et al. 2019). Those meetings focused on near-term eruption forecasting (2011), communications (2013), and long-term hazards assessment (2016). In 2019, over 80 people from 25 countries participated from observatories, government research institutions, and academia to discuss their experiences, challenges, and hard-earned successes during volcanic crises in their countries.

In this paper, we discuss ways that volcano observatories can prepare for their role during volcanic unrest and eruption (highlights are stressed in Fig. 3). Observatories at the meeting were asked to discuss their recent history of eruption response and to address the following questions: 1) Which of your actions were key to success in your response? 2) Were there any actions that you forgot or now wish you had taken, and what would you do differently? 3) What are three lessons you'd like the rest of us to take home and consider as the basis for best-practice recommendations? The suggestions were discussed in breakout and panel sessions and written as detailed notes by rapporteurs. Our writing team reviewed all presentations, and the series of rapporteur notes to prepare this manuscript. We recognize that some recommendations may be challenging to accomplish for all observatories, due to lack of resources, cultural barriers, or bureaucratic constraints (Newhall et al. 2020). Indeed, some observatories cannot realistically attain "best practices" in all situations, but they can still strive for "good practice" and they can avoid the pitfalls that occasionally interfere with successful volcano response. Finally, the manuscript includes a series of six case studies introduced at the meeting that illustrate some of the recommendations covered herein.

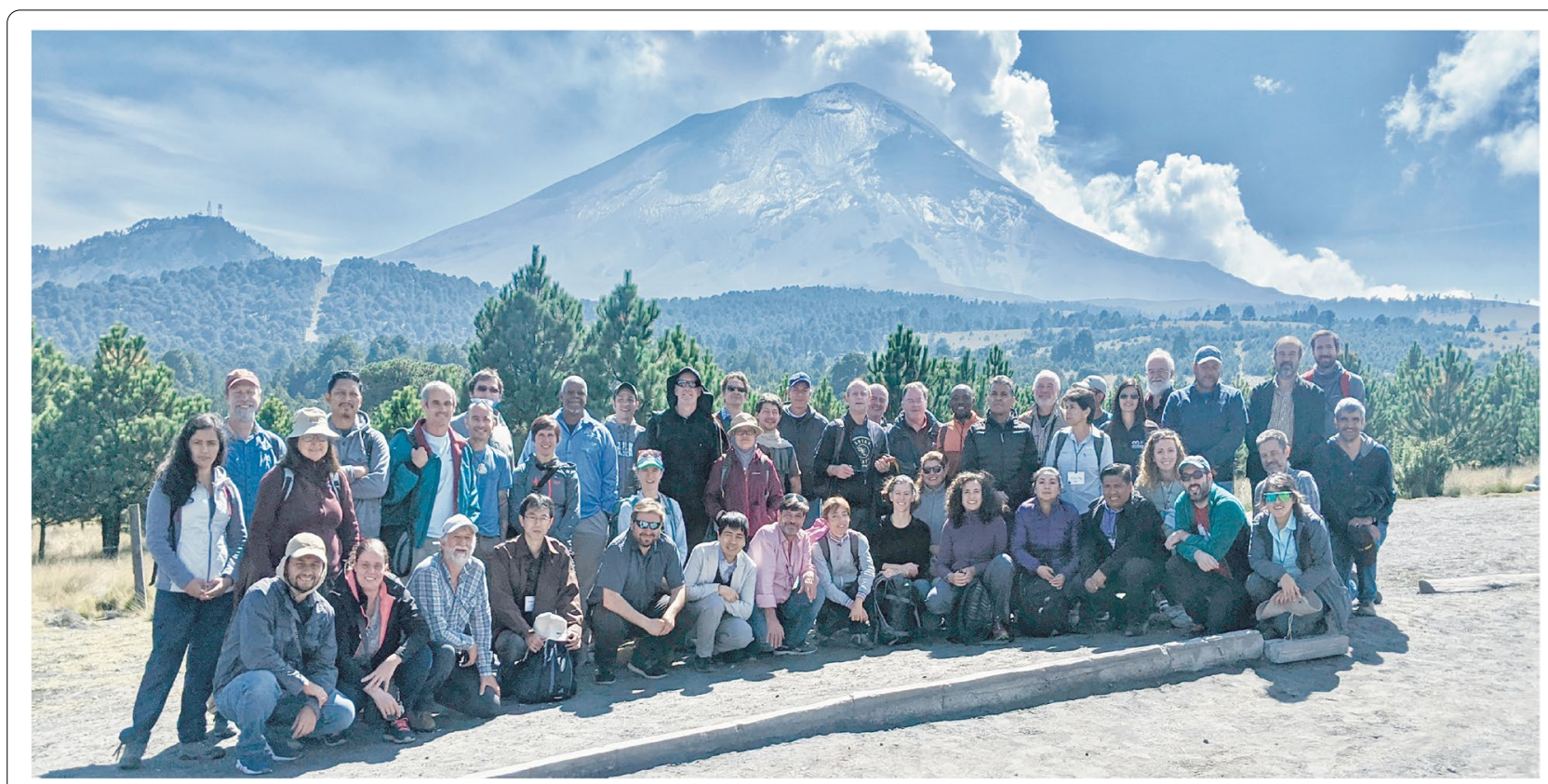

Fig. 1 VOBP4 attendees at the Paso de Cortes, with a spectacular view of Popocatépetl, 23 Nov 2019 


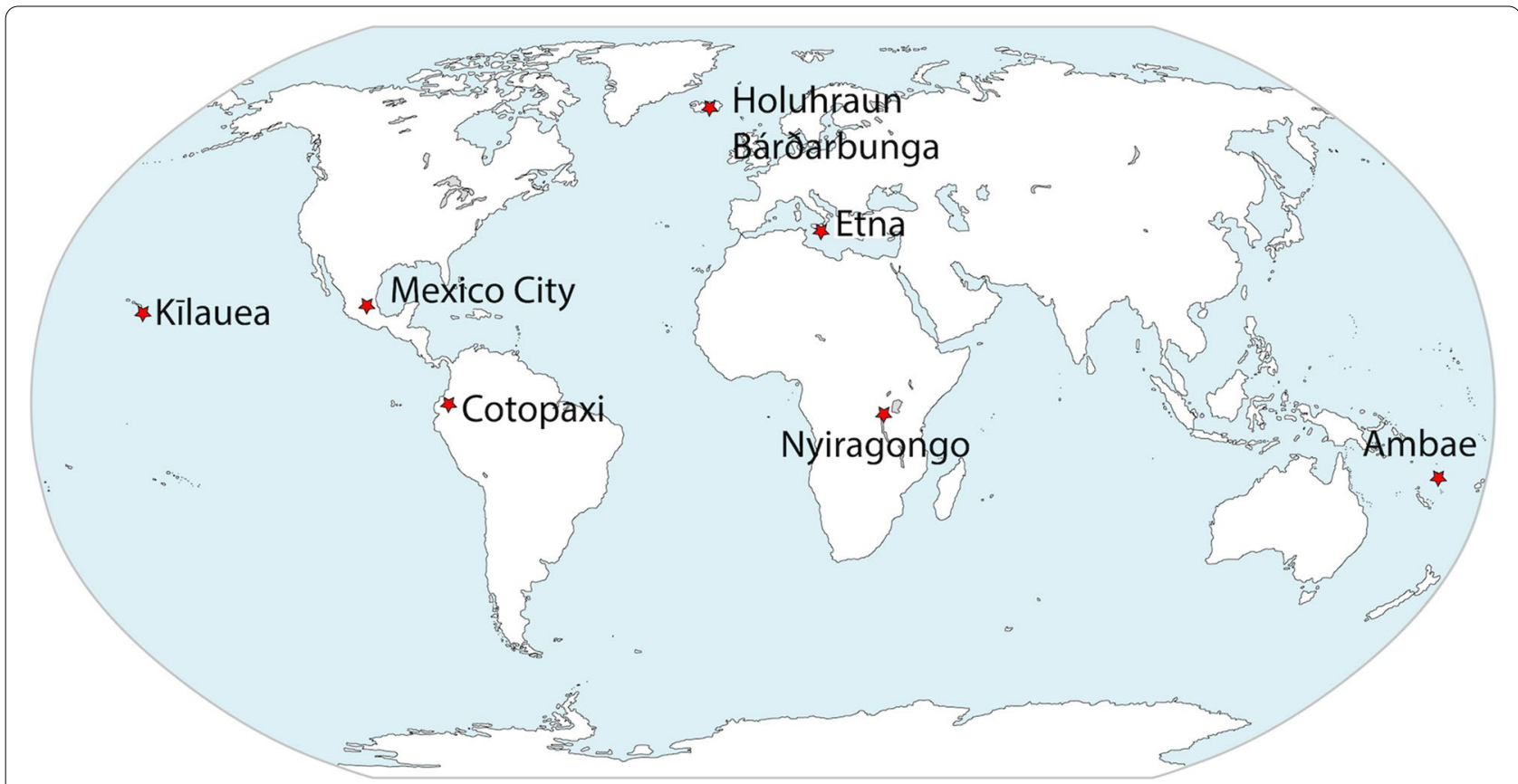

Fig. 2 Locations for the six case studies plus the venue for the meeting (Mexico City). Background map of the world from Vecteezy.com

\section{Good Practices for Volcano Observatories}

\section{Science and Data}

Design the Network to Match the Volcanic Threat Hazard and Risk Maps

Threat Assessments

Gap Analysis

Network Design

Create Protocols and Checklists

Documents and Templates

Record Decisons

Use Unrest Timelines

Write Communication Plan

Be Ready for the Data

Alarms

Models

Analysis and Archiving

Data Policy and Ethics

Organize

\section{Communicate}

Public Information Officer (PIO)

Regular Statements

Multiple Audiences

Social Media

Event Trees

VALS and VONAS

Response Maps

Structures

Training

Workforce Agreements

\section{Collaborate}

Interagency Response Plans

Academic Partnerships

Advisory Councils

Incident Management System

Exercises

\section{Post-Response}

\section{Assessment \\ What Worked? \\ What were Weaknesses? \\ How do we Improve Next Time? \\ Re-build Better}

Fig. 3 Suggested practices to aid volcano-response capabilities

\section{Scientific information-- networks, observations, and data}

Volcano observatories provide the scientific information needed to respond to volcanism, with the ultimate goal of communicating effectively with the authorities in charge of civil protection. Advanced preparation is essential to ensure that the observatory has the data, tools, and computer systems required to inform decisions. Monitoring networks are designed largely in response to the hazard posed by the suite of volcanoes in a region or country. In 


\begin{tabular}{|c|c|c|c|c|c|}
\hline \multicolumn{2}{|c|}{} & \multicolumn{4}{c|}{ THREAT LEVEL } \\
\cline { 3 - 6 } & & Low & Moderate & High & Very High \\
\hline \multirow{3}{*}{$\begin{array}{c}\text { MONITORING } \\
\text { NETWORK DENSITY } \\
\text { AND COMPLEXITY }\end{array}$} & Elementary & Good Practice & Underfit & Inadequate & Inadequate \\
\cline { 2 - 6 } & Intermediate & Comprehensive & Good Practice & Underfit & Inadequate \\
\cline { 2 - 6 } & Advanced & Oversized & Comprehensive & Good Practice & Underfit \\
\cline { 2 - 6 } & State-of-the-Art & Oversized & Oversized & Comprehensive & Good Practice \\
\hline
\end{tabular}

Fig. 4 Conceptual diagram of the simplified results of a volcano threat (risk) assessment and gap analysis, whereby volcanoes would be differentiated by their relative threat, with different levels of monitoring assigned to each threat level. In principle, volcanic threats could be scored comparably anywhere in the world. However, countries have different financial resources and scientific priorities, and what is considered elementary, intermediate, advanced, and state-of-the-art may vary

advance of an eruption, the observatory should strive to assess the hazards, undertake a basic risk analysis, characterize the existing monitoring network, identify any gaps in that network, and, with this information, seek to optimize monitoring. In addition, models, tools, alarms, and associated systems should be acquired and tested, as they will be required to respond to unrest at volcanoes.

\section{Volcanic hazard and risk maps}

The essential data needed to assess volcanic risks is the volcano hazard map, which is a graphical means to communicate the potential extent and magnitude of a wide range of volcanic hazards, including lava inundation, ashfall, ballistics, lahars and pyroclastic density currents (Calder et al. 2015; Thompson et al. 2017). Where combined with information on exposure and vulnerability of people and infrastructure, hazard maps form the basis for risk maps and risk evaluations. The topic of "Long Term Hazards Assessments" was covered as the focus of VOBP3, and Pallister et al. (2019) provide a discussion of hazard maps and their use by volcano observatories.

All hazard maps are based on the eruptive history of a volcano. For well-studied volcanoes, hazard is inferred based on the mapped products from past eruptions (e.g., Orsi et al. 2004). Where the geologic history is poorly known, maps may be based on analogue volcanoes and combined with local topography. Other maps may be based in part on results from semi-empirical or numerical modelling of a few eruption scenarios (e.g., Iverson et al. 1998; Esposti Ongaro et al. 2008; Kelfoun et al. 2009; Bonadonna 2006; Mothes et al. 2016a, 2016b; Barsotti et al. 2018), or probabilistic analysis of the results of numerous scenarios (e.g., Marti et al. 2008; Sandri et al. 2016). See examples at http://volcanichazardmaps.org/.

\section{Threat assessment and gap analysis (TAGA)}

Starting with the hazard map, observatories can then optimize monitoring by undertaking a threat or risk assessment (Ewert et al. 2005, 2018; Lara et al. 2006;
Miller 2010; Camejo and Robertson 2013; Barsotti et al. 2020). Using the best available hazard and exposure data, one can tabulate a risk score for each volcano relative to the vulnerable population and infrastructure (Ewert et al. 2005, 2018). Volcanoes then can be classified into groups such as low, moderate, high, and very high threat groups. In countries with only a few volcanoes, such differentiation may be unnecessary, but the overall assessment is useful in determining the appropriate resources to designate for effective monitoring. Assessments should be updated routinely as new information is gathered, a volcano becomes newly active, or a major change in exposure occurs.

Observatories may then consider their existing monitoring relative to idealized networks (Moran et al. 2008) for different threat categories (Fig. 4) and relevant to their funding and professional capabilities (both scientific and technical). Together with the threat assessment, this gap analysis permits prioritization for new installations justified by a cost-benefit analysis. The threat assessment can be crafted into a pamphlet or presentation to communicate to relevant government organizations and other funding sources that the observatory has carefully considered strategies for improved monitoring (examples being in Chile, Ecuador, El Salvador, Guatemala, Peru, and the USA). The TAGA thus represents a planning document, and an advertisement for the analysis, knowledge, and perspective that the observatory brings to volcanic-risk reduction.

\section{Monitoring networks}

The monitoring network provides the basis for any early warning of potential eruptions (Sparks 2003). Without monitoring to detect initial signs of unrest, the observatory can lose critical time and must rapidly "catch up" to gain information that can provide an understanding of the origins and potential outcomes of the new activity. Monitoring also helps to detect dangerous phenomena during and after the eruption, such as pyroclastic 
density currents and lahars. Installation should be carried out during a period of quiescence and the network maintained long enough to characterize the background activity levels depending on the type of data (e.g. years of seismic data are needed).

Even for low-threat volcanoes, it is important to maintain some real-time seismic monitoring to detect precursors for eruptions with rapid onset (Moran et al. 2008; Miller and Jolly 2014), such as at Reventador 2002 and Chaitén 2008 (Hall et al. 2004; Carn et al. 2009). Recent studies have shown that seismometers, even tens of $\mathrm{km}$ from the volcano, can detect pre-eruptive seismicity (Bernard et al. 2019; Fee et al. 2020) so it is not necessary to have a dedicated network at every low-risk volcano, especially if resources are not available. However, as the threat grows in space and/or time, the number and types of instruments should increase, enhancing detection of seismicity, ground deformation, and gas emissions (Sparks 2003; Galle et al. 2010; Sarsito et al. 2019). Remote sensing is an increasingly important complement to ground-based instruments (Francis and Rothery 2000; Reath et al. 2019; Poland et al. 2020). Space-based platforms can detect eruptions (e.g., thermal anomalies, ash clouds, morphological changes), provide estimates of gas emissions (e.g., TROPOMI), and allow tracking of deformation (InSAR and optical data). Lightning detection, infrasound, and telemetered visual and thermal cameras can also detect and characterize the eruptive activity. During eruptions, petrological monitoring of the eruptive products helps to recognize the ongoing magmatic processes and to better understand geophysical signals (Re et al. 2021). For that purpose, ashmeters and automatic ash samplers can be installed beforehand to ensure appropriate sampling (Bernard 2013; Shimano et al. 2013). Finally, the monitoring network should be adapted dynamically to the level of threat: if possible, spare equipment should be stockpiled for installation during crises.

\section{Tools}

During a volcanic crisis, there is enormous demand for rapid output of data products, activity status, interpretations, and decisions. Tools should be developed to facilitate and automate observatory products. We define digital tools loosely to represent algorithms, user interfaces, information portals, data visualizations, and numerical models. Digital tools should be used to simplify data streams, track trends, provide situational awareness, and issue information products; all are best developed in quiet times prior to a volcanic crisis.

\section{Alarms}

Critical tools can be developed to expedite response through alarms (e.g. seismic amplitude, infrasound detection, lightning detection, deformation) that notify duty staff when established thresholds are exceeded. The alarms ideally promote immediate action to interrogate the data record, to determine its significance, and to expedite a response. Creation of data-triggered alarms can ease the workload of observatory staff, and in some cases can avoid the need for 24/7 operations during a response (e.g., Section 8.5). As data formats become more standardized, tools can be more readily shared among volcano observatories. We recommend that volcano observatories, academic organizations and other geoscience institutes collaborate to facilitate development and peer-review of open-source digital tools that can be widely used by volcano observatories across the globe. Additional file 2 lists tools (and their purpose) developed for volcanology and used in volcano observatories around the world (Additional file 3 provides the associated references).

\section{Models}

Both conceptual and numerical models will inform impacts of potential eruption scenarios including ashfall, lahars, lava inundation, pyroclastic density currents, and toxic gas dispersion. With appropriate input parameters (e.g. Mastin et al. 2009 for tephra, Tarquini et al. 2018 for lava flows), numerical models can be integrated into information statements for alerting emergency responders and the public. Establishing default input parameters and using current wind models for ash distribution and ashfall models, for example, can be used for situational awareness, providing a forecast of what to expect if an ash-producing eruption were to occur at any given time.

\section{Real-time data analysis}

Data should be accessed, archived, processed, modeled, visualized, integrated, and distributed during a crisis in real time and continuously. It is fundamental to process and visualize scientific data in an integrated manner, over the same timeline and with common axes to integrate data collected at different frequencies. Plots should be generated in an automated pre-formatted template for immediate assessment of patterns, tendencies, and thresholds to aid evaluations and decisions. Ideally these systems incorporate multidisciplinary data (gas, seismic, geodetic, geologic) that can be used by a broad range of observatory scientists who participate in analysis and evaluation of insightful correlations. A variety of tools can assist with data organization, plotting, and visualization to aid decision-making. For example, the French volcanological and seismological observatories have developed operational software over the past two decades called WebObs (Beauducel et al. 2020). This set of web-based tools performs integrated, centralized, and 
automated real-time volcano monitoring. It promotes enhanced data processing, data analysis, interdisciplinary modelling, and exchange between researchers, engineers, and technicians during periods of unrest as well as periods of long-term quiescence. This allows scientists to test new methods with real time data and to instantaneously share their results in the community. The USGS developed software (VALVE) to plot multiple datasets on shared timelines, and to support exporting recent data plots to dynamic web environments. These and many other more specific tools are listed in Additional file 2.

\section{Data archives and databases}

Many of the data systems discussed above can export to global databases or interact with those databases to support decisions. Observatories can mine open-access volcano databases for key information on analog volcanoes or crises that, in turn, can aid assessments and forecasts. WOVODAT (Venezky and Newhall 2007; Newhall et al. 2017) is a long-standing effort to archive global data of volcano unrest, is open access, and can be queried to assist during volcano response. An increasing number of countries are actively partnering with WOVODAT during crises to help document volcanic activity (e.g., PHIVOLCS-LAVA; Costa et al. 2019). Contributions to such global efforts are helpful, because they enable volcanologists to make use of analogous observations, data, and outcomes from episodes of unrest. Other crucial data are available through the Smithsonian Global Volcanism Program (Global Volcanism Program 2013), which includes a catalog of eruption magnitude (Volcanic Explosivity Index) for all active volcanoes. Large eruptions of the Quaternary are covered by the LaMEVE database (Crosweller et al. 2012). Lava domes are covered specifically in databases like DOMEHAZ and GLADIS (Ogburn et al. 2012; Harnett et al. 2019).

\section{Use of scientific data}

During a crisis, the priority of the observatory and any advisory group is to acquire, process, and interpret data rapidly, so that the data can be communicated to civil protection authorities. Use of scientific data for peerreviewed publications can be developed in parallel, but must not dominate crisis management goals (IAVCEI Subcommittee for Crisis Protocols et al. 1999; IAVCEI Task Group on Crisis Protocols et al. 2016). At the same time, it should be noted that collaborating (external) scientists often make key contributions through innovative sensors, surveys, and modeling, all of which might have required significant financial and logistical investment. Hence, contributing scientists should ultimately be able to publish results obtained during the crisis, while observatory scientists who contributed data or key support should be included on publications (See Section 5.2 for a discussion of Academic Collaboration, and Section 6.1 for relevant Crisis Communications Plans).

Open access to data (e.g. IRIS Data Source for seismic data) allow colleagues and partners to quickly access and analyze eruption data. Moreover, identifying datasets of interest and pathways for their rapid release can benefit the observatory by allowing the academic community to process and share data quickly (e.g., the Supersite concept described in Section 8.6). Although data policies vary in different countries, we the authors and the majority of the VOBP attendees recommend that data be rendered openly accessible and widely distributed as soon as possible, especially in situations like volcanic crises where lives are at stake. It is key for observatories to become trusted and credible messengers of volcano data and hazards information. Part of building trust is sharing data with the scientific community and public as appropriate. However, it is equally critical that the scientific community (and public) use the data in a responsible manner and share any insights directly with the observatory so that they can be used seamlessly within the eruption response.

\section{Organization-- protocols and checklists}

Staying organized is paramount during any volcanic crisis. Observatories have developed numerous checklists, protocols and methods that can be shared and copied widely. In this section, we offer some ideas that may prove useful.

\section{Key documents to guide a response Protocol or policy document}

Is a predefined set of requirements for the kinds of products, services and information that a volcano observatory is expected to provide; allows discussion pre-crisis with other agencies and/or within a volcano observatory, so that there is clarity of roles and responsibilities during a response.

\section{Standard operating procedures}

(SOP) are predefined procedures created prior to a response that may include a checklist and/or graphical flow charts that ensure compliance to protocols during chaotic times (e.g. instructions for writing and issuing information products; instructions for updating and distributing talking points; sampling and analysis; field safety).

\section{Guidelines}

Are useful where a comprehensive policy or SOP would be over-prescriptive but basic boundaries are defined to 
facilitate operations, responses, talking points, etc. (Bretton et al. 2018).

\section{Checklists}

(e.g. calldown lists) ensure compliance to protocols during chaotic times when it is all too easy to forget what needs to be done. Newhall et al. (2020) provide further guidance on the use of checklists for crisis operations within volcano observatories with abundant examples and downloadable lists. With this article, we provide example checklists from the Alaska Volcano Observatory (USA) as Additional files 4, 5, 6, 7 and 8.

\section{Templates}

Are useful to develop in quiet times and can be readily populated during a crisis. A volcano observatory could consider developing generic templates for: 1) formal information products (e.g. Volcano Alert Levels (VALs), or more generic status updates) 2) an eruption chronology 3) talking points, 4) staff scheduling (various formats), 5) event trees, 6) sampling and analysis workflow, and 7) staffing contacts and availability. A set of spreadsheet templates for gathering chronological information during an eruption is provided as Additional file 9 and an example is given in Additional file 10.

\section{Documentation of communications and decisions}

During a crisis, the scientific response team should communicate in a regular, systematic, and frequent manner with authorities and the public using traceable and auditable documents (Section 3.1). Information forming the basis of recommendations should be recorded either through event trees (Section 6.4), minutes/logs for meetings, or daily internal reports from assigned staff. Scientific information and related reasoning should include interpretations, a summary of the possible outcomes and their related uncertainties, as well as a summary of key divergent opinions or alternatives. This documentation can be complemented by a catalog and timeline of observatory products that were issued during the response including: bulletins, reports, felt earthquake notices, alert-level statements, VALs, press releases, public statements, social media and web posts, interviews, photo, video and film footage that need to be timed and indexed with adequate metadata for data mining. Specific staff should be assigned to this fundamental task, as it will directly feed any postresponse assessment and related research by the observatory or its partners (Section 7.1).

\section{Unrest timelines}

In addition to a timeline of actions by the observatory, there will need to be one specifically for scientific data (e.g., Fig. 2 of Syahbana et al. 2019). Such documentation can provide input to global databases and allow thoughtful understanding of the progression of monitoring signals prior to eruption (or lack thereof). During the crisis, the observatory staff should maintain an electronic easy-to-use and user-accessible incremental timeline and repository of all the observations and phenomena. An example timeline for the 2008-2009 eruption of Redoubt Volcano used by the Alaska Volcano Observatory is provided in Additional file 10.

\section{People-staffing and training Staff structures and duty rota/rotations}

Establishing a structure to balance staff workload allows the volcano observatory to stay organized, focused, and appropriately staffed. New positions may be required that are not needed during normal observatory operations (e.g., liaisons, extra communications, documentation) and protocols/guidelines should be developed for all such roles well in advance of a response. Observatories that do not normally operate on a $24 / 7$ basis will need to identify situations where $24 / 7$ operations are needed or likely expected by civil protection agencies, aviation authorities and other decision-makers. Thus, contingency plans should be in place to increase staffing numbers rapidly if required. This could take the form of partnerships with other agencies (such as Met offices or civil protection) or academic institutions (Sections 4.3, 5.1 and 5.2).

For smaller responses (e.g. low-level eruption, remote, less impactful), a dedicated smaller number of staff can rotate as a duty team, responsible for tracking monitoring data and reporting observations under the oversight of the head of the volcano observatory. For example, this team can rotate availability to cover $24 / 7$ operations for a set time period (for example, a week). Small response teams are greatly aided by the availability of alarms (e.g. seismic amplitude, infrasound detection; Section 2.4.1) that are triggered when thresholds are exceeded. With appropriate structure, the remaining staff (even the head of the observatory) can stay focused on other responsibilities until it is their turn to act in a duty role. The 24/7 operations need not occur solely in the physical observatory, as duty staff can carry dedicated phones and may evaluate monitoring data from home or elsewhere, if the data are available through web interfaces or software tools such as dashboards. A duty-team structure enables cross-training among staff scientists and technicians where staff share the responsibility of assessing a wide variety of monitoring data, effectively widening the knowledge base of the observatory staff, encouraging mutual trust, and allowing the director to delegate authority. 
During escalating activity, the duty-scientist structure is still very effective. However, it may need to be augmented with additional data checks by other staff on a defined schedule, thereby reducing the workload on the duty team.

For large responses (e.g. high impact, large volume), the observatory may decide to develop a more formal response coordination team with roles such as chief of operations, science coordinator, hazards information coordinator, public information officer, monitoring network lead, information technology (IT) lead, operations scientists and an emergency liaison officer. A formal staffing structure provides leadership and oversight to help keep the response organized, thorough, and staff less prone to fatigue. An example of a response coordination team and potential list of duties is provided in Additional file 11.

\section{Staff training}

Observatories will be better prepared for emergencies if their staff members are familiar with their potential roles during a crisis, perhaps as part of an emergency management system (e.g. Incident Management System or IMS: Section 5.4). This means that meetings, training, and exercises are needed to practice familiarity with crisis protocols. Everyone should regularly review protocol documents, SOP's, guidelines, checklists and templates that will be used. Staff meetings (which may include external partners) are an effective way to stay connected, hold discussions, and practice exercises. Event responses can be complex and joint exercises with emergency management officials and other key stakeholders in advance of a crisis are critical. If an emergency management or other formal structure is used during a response, and it is not part of normal operations, staff should study and exercise the roles and responsibilities of observatory staff in advance of a crisis.

\section{Workforce agreements}

Most observatories do not have 24/7 operations, thus demands on core staff during crises necessitate workforce agreements to bolster human resources. Examples might include: 1) enlisting qualified individuals or agencies to provide additional off-site data checks, 2) establishing cooperative agreements with university colleagues to perform operational or research tasks, 3) inviting colleagues from other (in-country) observatories to visit and perform shifts and fieldwork tasks, 4) utilizing international teams to advise and augment instrumentation and response (Lowenstern and Ramsey 2017; Syahbana et al. 2019). All such agreements need to include well-defined roles and responsibilities and be made well in advance of a crisis to identify and develop pathways for permissions, visas, protocols for communications, etc.

\section{Collaborating with other agencies and groups}

A critical issue for an observatory is to recognize where its responsibilities stop and those of other agencies start. Each country has a different governmental structure (Fig. 5) and different legislative context, within which regional variations are common. It is important to identify how to interface with agencies responsible for risk and emergency management and other potentially dangerous natural hazards (e.g., earthquakes, weather, floods), land use management, etc. Furthermore, it is important to know what other groups can help the observatory fulfill its mission (IAVCEI Subcommittee for Crisis Protocols et al. 1999; IAVCEI Task Group on Crisis Protocols et al. 2016). Formal agreements are an important step toward a successful crisis response. Formal documentation and the shared understanding built through the development of the documents provides safety for both the volcano observatory staff and the other responding agencies and does not rely on single individuals (e.g., Section 8.3 on Mt. Etna response).

\section{Interagency response plans}

Volcanic crises necessarily involve a variety of agencies and stakeholders external to the volcano observatory who have their own responsibilities and accountabilities. A well-coordinated response with consistent messaging is required to facilitate the flow of timely and useful information to those at risk. A formal interagency operating plan provides guidance for an integrated, multi-agency response by describing the roles and responsibilities of each agency. Such plans are supported by detailed standard operating procedures that are maintained by each agency or stakeholder (Washington Military Department Emergency Management Division. Coordinating efforts between governmental agencies in the event of volcanic unrest at Mount Baker or Glacier Peak 2012; Alaska Volcano Observatory, National Weather Service, Federal Aviation Administration 2017; ONEMI (Chile). 2018; UNDAC 2018). Many of these agencies and stakeholders deal with frequent crises, very few of which are volcanic in nature. Their staff may not be familiar with volcanic eruptions, or they may be newly hired since the response plan was first written. Consequently, written response plans are an important reminder of what to do and whom to contact, and they can be useful both to the observatory and the other agencies. Response plans should be updated regularly. A means for implementing updates is through interagency working groups that meet periodically to learn each other's missions and requirements, 


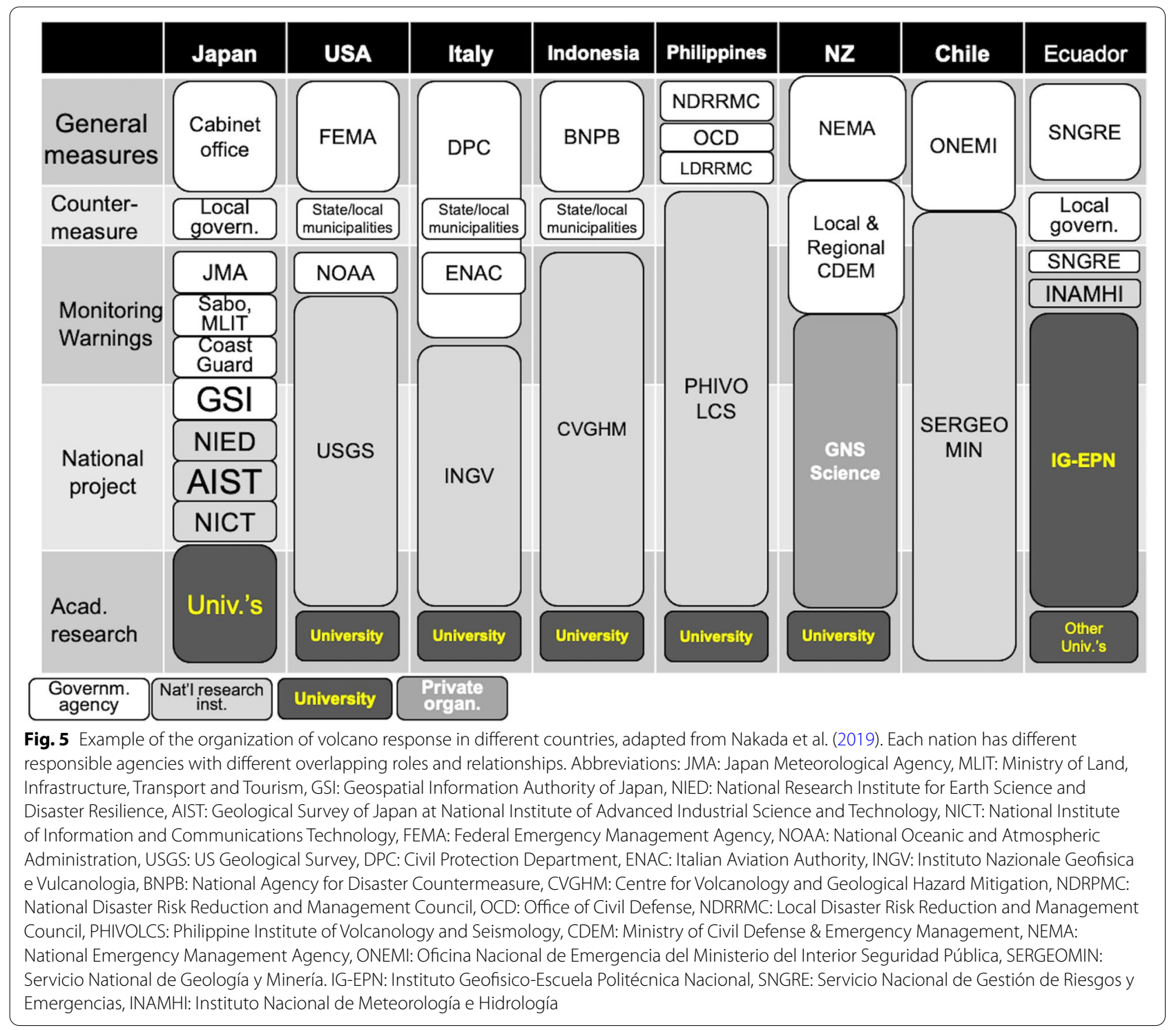

undertake exercises to practice and enhance the plan (e.g. scripted and unscripted scenarios and exercises (Section 5.5), as well as training), and allow for familiarity that will be critical during a crisis.

\section{Academic collaboration}

External academic partners are an excellent resource during eruption responses as well as during quiescence; they often have time and energy to focus on specific aspects of an eruption response (sampling, analyses, tool development, modeling, etc.) and are not immersed in the operational response. Academic partners, however, will have other responsibilities such as teaching and student supervision and so a volcano observatory should understand and acknowledge the different pressures they might be under. Academic organizations may also provide additional personnel (students) or laboratories for tasks such as sample collection, processing and analysis and partnering provides unique training opportunities for students and a potential source of future employees for volcano observatories. Developed relationships and collaborations make it easier to incorporate academic colleagues to assist during a response. Existing relationships will help to minimize conflicts that may arise between observatories and external researchers, which have been highlighted during past crises (IAVCEI Subcommittee for Crisis Protocols et al. 1999; IAVCEI Task Group on Crisis Protocols et al. 2016). All parties involved in a response should abide by the protocols for professional conduct of scientists during crisis as well as the guidelines on the 
roles of scientist involved in volcanic hazard evaluation, risk mitigation, and crisis response (IAVCEI Task Group on Crisis Protocols et al. 2016).

\section{Advisory councils}

Science advisory councils provide focused support and oversight during crises (Doyle et al. 2015). Some observatories are defined by a consortium of academic and government entities working together to study and monitor volcanoes, where the monitoring and operational tasks are the responsibility of the government and the academic sector forms the science advisory council to advise on data interpretation, hazards and geologic history of the volcano (e.g. Mexico, Montserrat). For some, the operational load during a response is so great that the observatory benefits from enlisting an advisory council to focus on certain subjects. Councils may help to advise on particular hazards, to select appropriate external collaborators to perform analyses, to develop tools, or to provide oversight to ensure all scientific opportunities are maximized. They can also provide external scrutiny of the advice being provided by the volcano observatory. It is important to set up advisory councils prior to the response and to ensure that its members are collaborative and balanced, while bringing critical expertise and reputation.

\section{Incident management system (IMS)}

An IMS is a standardized, scalable, hierarchical emergency management system sometimes implemented to manage complex disasters, before or after an eruption has begun (e.g. FEMA 2017). Within an IMS, the volcano observatory continues to act independently, but some of its functions may have logistical and communications constraints imposed upon it (Driedger et al. 2008) by IMS team members occupying incident management roles. An IMS enables interagency interoperability and consistency among national, regional and local agencies and can leverage needed resources to reduce impact and expedite recovery (Perry 2003; Annelli 2006). This may come in the form of sharing; for example, pools of money, human resources, or emergency relief aid. If an IMS is routinely used during crisis response, the observatory team should be trained and familiar with their roles and responsibilities. Protocols and authorities that an observatory may have during normal operations may vary under an IMS and therefore it is critical that observatory staff be provided training to avoid conflict with police, military, government administrators, and others who may be directing risk mitigation and humanitarian response. Volcano observatories should work to ensure that their procedures link seamlessly with other responding agencies using an IMS.

\section{Exercises with partners and the public}

After all the planning, agreements, and communication strategies are developed, it is critical to test them with exercises. The scientific community can use them to engage governmental officials and to gain their trust, while also fostering public awareness of volcanic risk. Exercises provide invaluable tests for emergency plans and communication procedures. From the scientists' points of view, they are effective ways to learn expectations and needs of the civil protection community, and they allow volcano observatories to prioritize their products. As such, planned exercises are a critical best practice for the volcano observatory, and they should be repeated frequently to account for continual changes in institutional staffing.

In the field of volcanic risk, there have been several examples of simulations, both table-top (e.g., Pierson et al. 2013; Asgary et al. 2020) and full-scale functional exercises (involving all the components from scientists to civil-protection components, politicians and the public). Examples of the latter include the Mesimex at Vesuvius, Italy in 2006 (Barberi and Zuccaro 2004) and Exercise Ruaumoko 2008 in Auckland, New Zealand (Ministry of Civil Defence and Emergency Management 2008). A whole series of exercises related to the VUELCO project were discussed by Bretton et al. (2018), including those at Colima (Mexico), Campi Flegrei (Italy), Cotopaxi (Ecuador) and Dominica (see https://vhub.org/). Most recently a European scale exercise took place within the FUTUREVOLC Project when an eruption in Katla volcano was practiced (Witham et al. 2020).

From these and other reports, we can conclude that the keys to successful exercises include: 1) early organization (weeks to months ahead); 2) active participation of scientists in the scenario design; 3) accounting for the multi- and cascading-hazard impacts of the eruption, including, for example, ballistics, density currents, tephra fallout, flooding, fires, etc.; 4) participation of scientists, civil protection, and relevant stakeholders; 5) a mechanism to test information flow among the different groups of scientists and responders; 6) time for all participants to debrief, discuss the exercise and its results, and plan for subsequent actions.

In contrast, obstacles to successful exercises include poor organization, unclear goals, a vague volcanic scenario, and inadequate post-exercise debriefings. One continuing challenge is how to organize the timing for phases in an exercise. Each phase might represent a different time span (e.g., 6 months of unrest data may be covered in a single morning, whereas 2 weeks of data may require an entire afternoon), and this may hamper scientists' ability to consider all possible parameters that would normally 
be required for accurate forecasts. For this reason, it is worthwhile to plan for and incorporate the most critical discussions and decisions that will test the capabilities of the observatory and its partners in a drill that is compressed in time, and yet ambitious in scope.

\section{A spectrum of communications challenges}

In times of volcanic unrest and eruption, successful communication can save lives (Andreastuti et al. 2015; Fearnley et al. 2017). Volcanic risk is mitigated only through community action in advance of active volcanic hazards. This requires excellent communications within the observatory, with partners, and with stakeholders. To be successful, the volcano observatories must be a trustworthy source of evidence-based hazards information (Bartel et al. 2020). Trust is an earned trait and trustworthiness takes time to establish (e.g., Cotopaxi Case Study in Section 8.5). Therefore, it is good practice for volcano observatory personnel to develop relationships with communities and emergency managers in non-crisis times when education efforts can be focused on understanding potential hazards, preparation for crises, and building resilience.

\section{Crisis communications plans}

Plans that outline communication pathways are valuable tools that volcano observatory staff can follow like a script during response to volcanic unrest. Such plans lay out protocols for information flow both internal to the observatory and external, to emergency-response partners, media, and the public. It is beneficial to develop and practice these plans in non-crisis times in order to avoid oversights that might lead to confusion during a volcanic eruption. Similarly, volcano observatory leaders and public information officers (PIOs) should establish relationships with reporters from local news media so a personal and trusting relationship is established ahead of a crisis event.

\section{Communications tools, teams, and protocols}

Transparent and open communication between volcano observatory staff is crucial in a crisis.

Potential communications tools and protocols could include:

- Digital collaboration applications that provide a platform to communicate via any device in a secure way (e.g., Mattermost, Section 8.2).

- Call-down lists that ensure observatory and emergencyresponse staff are fully briefed in a crisis situation.

- Established roles with predetermined responsibilities that help maintain a cohesive flow of information during a crisis.
- A pool of duty communicators that includes skilled, trained communicators with expertise in specific volcanoes and eruption processes.

- An observatory-designated PIO who can participate in hazards-response training and develop plans for communicating with the media and public (e.g. social-media plans).

\section{Regular team meetings}

These may include partner agencies (e.g., emergency response or land management) and provide opportunities for staff to share the latest findings from various monitoring disciplines. If in-person meetings are not possible, or if time does not permit, discussions can take place via a digital collaboration application (e.g., Slack, Mattermost, Microsoft Teams) or other internal communication tool (e.g., observation logs).

Additional meetings could be scheduled to discuss specific topics such as event trees (Section 6.4) or scenario development. As needed, the results of such meetings should be shared externally (discussed below). In these meetings it is important to be inclusive in order to attain multiple viewpoints and to express the range of possible outcomes. The meetings should have a clearly defined agenda.

\section{Event trees}

Event trees are a useful way for observatories to consider the likelihood of a wide variety of potential outcomes from an episode of volcanic unrest (Fig. 6). They can be used as the basis for communications statements or decisions to assign additional monitoring or personnel resources to the crisis. Probabilities can be assigned by varied procedures that can range from:

- a simple group consensus (e.g., Newhall and Hoblitt 2002; Wright et al. 2019),

- a mean score in a survey (e.g., Syahbana et al. 2019),

- a more formal rating by a group of solicited experts (Aspinall and Cooke 1998),

- or a calculation based on monitoring data, global volcano data, and predefined thresholds (e.g., Marzocchi et al. 2004, 2008).

At a minimum, the event trees provide a platform for group discussions and consideration of varied perspectives, as well as a framework to document how the observatory staff interprets the current data. Event trees are complex and can be used to report both hazards and risk. It is best for observatory staff to understand their use and be comfortable with assessing probabilities well in advance of a crisis (e.g. Newhall and Hoblitt 2002; Marzocchi et al. 2010). When monitoring 


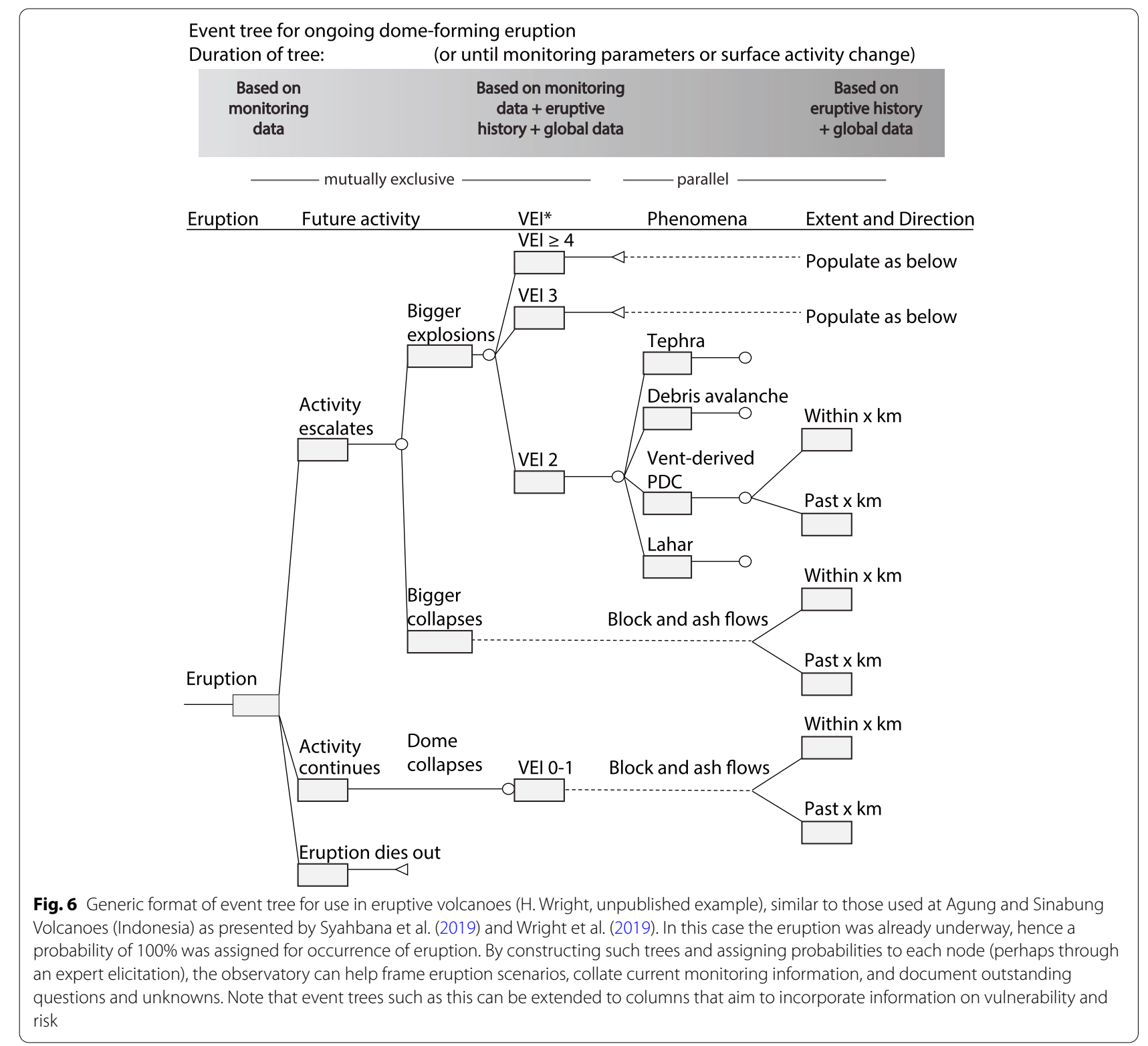

thresholds are determined prior to any unrest (Marzocchi et al. 2008), they facilitate understanding and are a valuable means to inform civil authorities of the potential ways that a volcanic crisis can unfold (Newhall et al. 2020). Event trees are therefore also a way to plan for the impacts from future eruptions (see Section 8.4 example of Bárðarbunga, Iceland).

\section{External communication products}

Of primary importance, interagency response plans (Section 5.1) are critical for understanding how to share communications responsibilities with civil authorities, universities, and other partners/ stakeholders. Joint information centers may be set up through such agreements or may be a SOP in an IMS (Section 5.4).

Per observatory requirements, a variety of communication products can be used to reach broad audiences, including emergency-response partners, land managers, the media, or the public. The most effective crisis-communication products combine hazards information with actions to take (Leonard et al. 2008), whether that be specific safety information or suggestions to follow up with state and local emergency management agencies. Most observatories use some sort of VAL (volcanic alert level) to communicate changes in activity and relative hazard 
(Fearnley 2013; Potter et al. 2017; Pallister et al. 2019). Some volcano observatories do not use VALs when the communication of hazard, risk, and mitigation action is the role of emergency responders (Papale 2017) rather than the observatory. Ideally, if a VAL is used, the observatory will have well-defined alert (or activity) levels that incorporate the diversity of possible volcanic behavior. And it is recommended that the observatory will have worked together with emergency responders before the crisis regarding their use of VALs. Indeed, VALs should be well understood by partner agencies, especially those responsible for public safety. Additional useful communication products include Volcano Observatory Notifications for Aviation (VONA), and information statements possibly including forecasts and scenarios, or discussions of alert level changes. The topic of near-term forecasts and their uncertainties was covered in the VOBP1 meeting (Pallister et al. 2019).

Many countries have developed applications and specialized websites to deliver hazard-relevant information. The HazardsHunterPH by PHIVOLCS allows users to get geographically tailored risk analysis in the Philippines. Magma Indonesia is optimized for users to obtain the latest alerts and data on their smartphones. The ECU911 system is run by an emergency management agency in Ecuador and includes natural hazards as well as many other potential risks. The USGS Volcano Notification Service sends texts and emails to subscribed users as well as to designated websites and systems.

It is crucial to communicate with empathy when conducting any type of public media response, either via social or traditional media methods. One must visualize the situation of the impacted community, the emergency response staff, and observatory colleagues. It is important to communicate in regularly scheduled intervals. Even when the eruption is in a steady state, it is crucial for the public, especially vulnerable communities, to know that nothing has changed. This could manifest as regularly scheduled information statements or short updates that can be posted to websites and social media.

\section{Social media}

Social media accounts can greatly enhance the connection of an observatory to the public (Sennert et al. 2015). When accounts are established in quiet time, volcano observatories have the opportunity to provide an interactive way to engage the public. Educational posts aimed at volcano-hazard comprehension encourage a two-way communication between followers and observatory scientists, which builds trust. Scalable social-media, crisis-communications plans should be developed, because demand for eruption status and situational awareness will be heightened as volcanic activity and potential hazardous situations ramp up. Developing pre-crisis relationships with influencer accounts (e.g. reputable organizations, regional volcano-science accounts, respected volcanologists), wherein those accounts agree to amplify observatory messaging can increase institutional trust and reach of official hazards messaging.

During unrest, the PIO may spearhead or work with a separate liaison(s) to regularly post and reply to comments on social-media accounts. These posts may include photos, videos, and new developments as the volcanic crisis progresses. Social-media accounts can act as a conversational tool providing a place for followers to ask questions and have them answered. The effect is a more educated and trusting audience. Social media can also serve as a useful citizen-science tool where people who have been impacted by the volcanic crisis can report on events taking place.

Eruption videos can be an outstanding means for helping people understand complex processes and see the impact of eruptions. Such videos (e.g., VolFilm series) can be shared prior to events. During crises, videos of eruptive activity filmed by observatory or partner scientists and local citizens can provide valuable and relevant situational awareness for impacted communities.

\section{Hazard and risk maps as communications products}

One challenge in the development of best practices for hazard maps is to recognize the extreme heterogeneity in how hazard maps are prepared, what they represent, and how they can be used (see many examples at volca nichazardmaps.org). Because maps can guide decisions on exclusion zones and evacuations, both observatories and responding agencies should consider how a map was made and what it displays. As described in the Ambae case study below (Section 8.1), officials decided to evacuate an entire island based on a long-term hazard map depicting the extent of all documented past eruptions, even though the precursory and eruptive activity was confined to the summit caldera. In this respect, good practice is to produce dynamically evolving (e.g., timeevolving for short-term purposes) and fit-for-purpose hazard maps (Sandri et al. 2012), with appropriate versioning and date stamps. Short-term maps produced during crises evolve in time as monitoring data inform the likelihood of a particular eruption scenario or predicted vent position (Sandri et al. 2012; Surono et al. 2012; Thompson et al. 2017; Barsotti 2020).

\section{After the response}

Once the crisis is over, it is time to assess how effectively the observatory responded and to evaluate its performance, protocols, and plans (Fig. 3). Once the eruption 
has stopped or if the situation is being successfully managed, it is appropriate to start self-assessment. Indeed, it is never too early to begin to organize and archive the documents, communications, and undertakings that were part of the response and that allow the observatory to understand and evaluate its actions. If the observatory has followed the practices noted above in Section 3, it will be well prepared to start a thoughtful post-response assessment.

\section{Post-response assessment}

A formal assessment is a critical tool to ensure that the observatory builds on its successes and instills a culture of continuous improvement. Frequent questions to be addressed include:

- Was the response consistent with existing contingency plans?

- What could have been done better?

- What shortcomings were identified?

- Did communications reach the necessary audiences in a timely manner?

- Are new monitoring strategies needed?

- What new protocols and procedures should be developed for the next observatory response?

- What new partnerships will strengthen the observatory?

The outcomes of a post-response assessment will help in re-writing procedures, improving monitoring networks, re-organizing teams and staffing, and determining which interagency linkages were critical to success. Occasionally, the assessment can be undertaken by an external group, in association with observatory staff and associates (e.g., Williams et al. 2020). Other times, a report might be written by neutral observers with the aim of analyzing the crisis (Fiske 1984; Voight 1990).

The assessment can be undertaken through a workshop, including observatory partners. Alternatively, it may also be appropriate to use informal surveys or interviews to gather data on the range of opinions held by staff and collaborators. The results should be written in documents that can be shared within the organization and, ideally, can also be shared with partners and the international volcano community. To be most effective, a short summary of findings, translated into one or more relevant languages, will enable widespread use of the results. Research and operational staff can also summarize the response to provide a hybrid report on how the scientific teams and socialization staff (aka communications team) contributed to a response (Syahbana et al. 2019).
In some cases, it may be over-ambitious to expect under-resourced observatories to have the time and focus to complete a formal after-response assessment, but it is important to take some time to write up an informal document that expresses the overall lessons learned that can improve any future observatory operations. After all, contingency plans and standard operating procedures are living documents, meaning that they are subject to regular review and dynamic updates. Once the observatory identifies the major lessons learned, it needs to plan improvements, and staff who will be responsible for implementation. The post-eruption period is ideal for such updates: an example for the Bárðarbunga/ Holuhraun eruption is presented as Additional file 12.

Scientists can also share the outcomes of such an assessment by publishing scientific articles that might support and encourage other volcano observatories to undertake and establish lessons learned by others (Young et al. 1998; McCausland et al. 2019; Neal et al. 2019).

\section{Taking advantage of post-event prominence}

It's worth noting that in the aftermath of a volcanic eruption, or even a notable example of volcanic unrest, there may be considerable attention focused on the observatory and its partners. In this perspective this phase could be a chance to justify improvements to buildings, equipment, networks, and staffing (Newhall et al. 2020). National governments may be willing to provide hazard relief to replace lost equipment, as was the case after the 2018 eruption of Kilauea. After the 2008 eruption of Chaiten, the Chilean government created the RNVV (Red Nacional de Vigilancia Volcánica), a new country-wide network for volcanic vigilance (Muñoz and Moreno 2010), and an expanded volcano observatory in Temuco. The Indonesian government funded new observatory buildings at over 15 volcanoes in response to the 2017-2018 eruption at Agung Volcano (D. Syahbana, personal communication, 2019). If the eruption experience has helped identify weaknesses in the observatory or scientific knowledge gaps, this post-eruption time period may be an appropriate time to address those shortcomings with new programs.

Similarly, the public's increased interest in volcano monitoring and volcanic risk provides a short window for providing educational lessons or "teachable moments" whereby the observatory staff can reach new audiences, and gain trust through special websites, social media events, books, or other materials.

\section{Case studies}

Ambae, Vanuatu, 2017-2018: use of volcanic hazard maps and alert levels as guides for evacuations

The Vanuatu Meteorology \& Geo-Hazards Department (VMGD, http://www.vmgd.gov.vu), through its 
Geo-Hazards Division, is the national agency mandated to provide volcano monitoring capability to Vanuatu and related science advice to its government. Ambae (Aoba) is a small island in the Vanuatu archipelago. The local population lives mostly on the fertile and more accessible lower flanks of the volcano. A large-scale eruption 400 years ago built a volcanic cone in the summit caldera, where one of its craters is now filled by Lake Voui. Historically documented eruptions occurred in 1530, 1670, 1870, 1915, 1966, 1995, 2005 and 2016, and all took place solely at the summit, with the exception of the 1670 flank eruption which also produced some lava flows on the flanks of the volcano. Throughout this time, tephra fall only rarely impacted the populated areas further down the flanks, and there was no direct risk to life outside the immediate proximity of vents in the uninhabited caldera.

A period of sustained unrest began in 1991, culminating by an eruption in 1995, and followed by a decade of general quiescence. Ten years later, a significant eruption occurred in 2005 , followed by a smaller one in 2016 . As the level of activity increased in 2017, there was concern that the activity may not remain confined to the summit area and so long-term hazard maps were drafted to communicate the range of potential hazards on the island to the government and general public. Using that information, and the assignment to VAL 4 by VMGD (out of their 5-level system), the Council of Ministers made the decision on 28 September 2017 to fully evacuate the island of all 11,600 inhabitants. It was the first time in the history of the country that a full-island evacuation was triggered in a region regularly affected by volcanic eruptions, earthquakes, and cyclones. The evacuation was motivated by the VAL 4 and the unavoidable level of uncertainty around the location, timing, and severity of future activity, and also influenced by the decision-makers' interpretation that the whole island was at immediate risk. In contrast, the most likely scenario based on monitoring data, was for the summit vent to remain the locus of activity-hence not posing direct risk to life safety for inhabitants outside the caldera.

After the decision was made, Ambae's evacuation began on 4 October 2017. In the following weeks and months, the level of volcanic activity decreased and became less variable. Driven by the low immediate risk to life in the inhabited areas, repatriation of part of the population occurred mostly from 22 to 27 October 2017.

Volcanic activity remained low until mid 2018. However, variable yet sustained ash emissions persisted. On 26 July 2018, ash emission peaked and its cumulative impact dramatically affected livability at villages and agricultural areas on the flank of the volcano, due to severe damage to houses, agricultural subsistence crops, and cattle. As a result of these impacts, in spite of the VAL being at levels 2 and 3 (i.e., lower than when the island was first evacuated), the decision was made to re-evacuate the island's entire population.

A first major lesson from this evacuation is the critical need to prevent confusion between long-term, background hazard and risk maps (Fig. 7) and more relevant response maps tailored to the current crisis (see Section 6.7). Simple tools such as versioning and dating of all maps and documents, and clear communication by the subject-matter experts with stakeholders of the purpose, scope and timeliness of crisis-response, hazard maps are important to ensure decision makers are using the most relevant information. It is imperative to prepare and use the most relevant hazard maps to evaluate appropriate evacuations.

A second lesson is that VALs themselves are not always ideal thresholds to trigger evacuations. In the case of Ambae, two full-island evacuations were carried out: the first at higher VAL, due to (misunderstood?) concerns about immediate risk to life, and the second at lower VAL, rightly motivated by chronic habitability concerns due to the impact of accumulated ash.

It is important to note that when looking at VALs from a global perspective, observatory-released VALs have widely varying founding principles and messages/ meanings depending upon country or local government jurisdiction (Potter et al. 2017); they range from offering a snapshot of the current status of volcanic activity to conveying a forecast of future activity and/or include an assessment of the associated risk. In the end, authorities should use the VALs to assist in decisions, and as valuable prompts for discussions with observatories and stakeholders. By separating decision processes used to make the VAL (determined by the observatory) from those used to decide evacuation (determined by land managers or emergency responders), both parties can independently and rationally make decisions without interference from the other (Papale 2017).

\section{Killauea volcano, United States, 2018: digital collaboration creates a virtual observatory}

Killauea Volcano on the Island of Hawai'i had been erupting nearly continuously since 1983 when a dramatic shift occurred in May 2018. Over the course of the 35-yearlong eruption, the USGS Hawaiian Volcano Observatory (HVO) monitored the volcano's activity and issued regular public updates. HVO staff also developed close partnering relationships with the land and emergency management agencies responsible for ensuring safety. Several times through the decades-long eruption, Island communities were threatened by outpourings of lava and volcanic gases-some were completely destroyed. In these times, frequent communication with partners was 


\section{DRAFT AMBAE LONG-TERM BACKGROUND VOLCANIC HAZARDS MAP}

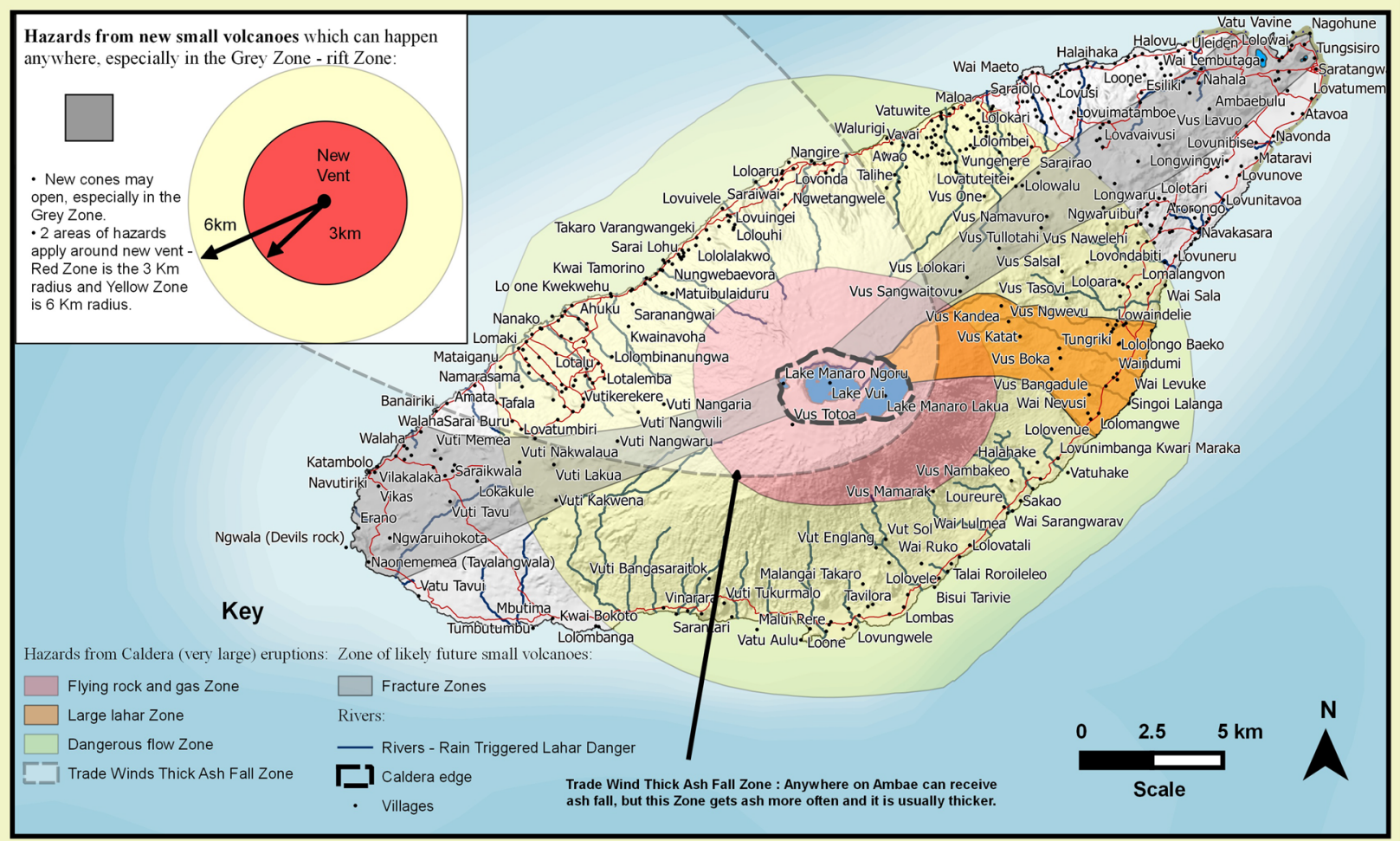

Fig. 7 Draft long-term volcanic hazards map of Ambae, Vanuatu, used during the 2017 eruption response to inform the government of potential hazards on the island. The insert focuses on hazard zones near the summit ( 3 and $6 \mathrm{~km}$ radius) and along the rift zone (in grey). Information about actions to be taken in different areas were provided by government agencies

critical, and, through the decades, the communication landscape evolved from infrequent telephone calls to asit-happens photographs and messages delivered to and from handheld computers/phones.

On April 30, 2018, the 35-year-long eruption plumbing system at $\mathrm{Pu}^{\prime} \mathrm{u}$ ' $\overline{\mathrm{O}}^{`} \mathrm{o}$ crater was breached. The lava lake within the crater drained and earthquakes began progressing eastward as magma migrated through Kilauea's East Rift Zone. Cracks began to form in people's backyards in the Leilani Estates neighborhood, which on May 4 became the locus of an eruption that displaced residents, destroyed hundreds of homes, and changed people's lives forever. Simultaneously, Kilauea's summit lava lake drained, and the caldera partially collapsed. These changes triggered hundreds of earthquakes per day that rattled many areas nearby and sent fine ash downwind (Neal et al. 2019). Not only were the two eruptions ongoing, the HVO building was severely damaged in the summit earthquakes and staff were displaced to a temporary observatory set up at the University of Hawai'i at Hilo, $40 \mathrm{~km}$ NE of HVO.

The combination of all these changes presented a new communication challenge to $\mathrm{HVO}-$ managing 24/7 monitoring of two simultaneous eruptions while conveying information as quickly as possible to emergency and land management partners. Fortunately, there was a precedent for methodology to keep scattered staff connected. The Alaska Volcano Observatory had demonstrated the utility of a collaborative, open-source, online messaging platform called Mattermost for internalobservatory communication during the 2016-2017 eruption of Bogoslof volcano in the Aleutian Islands (Coombs et al. 2018). On May 10, HVO successfully adopted the platform, which served as a successful means for handling communication for scientists involved in the eruption monitoring and response.

Mattermost was the tool that enabled timely situational awareness to be gathered for delivery to emergency organizations and kept distally scattered response team members continuously communicating with each other. Scientists from all five U.S. volcano observatories and the Volcano Disaster Assistance Program (VDAP) were involved in the eruption response, which meant that people were separated by thousands of miles. The application could be downloaded and used via either desktop/laptop 
or mobile device, and people involved in the response were given login credentials. In effect, Mattermost was akin to an intra-observatory social media platform where the shares, likes, and discussions were all about the two eruptions of Kilauea. All subscribers could read and post information, but "channels" were also organized with specific purposes by specific days.

1. Location-specific eruption-monitoring channels were reserved for reports from the field and included photographs, status updates, geographic coordinates, and need-to-know, emergency-related information. This channel was critical for providing minute-byminute reporting of events to observatory scientists who were stationed at joint emergency operations centers in Hilo and Honolulu. These scientists worked directly with county, state, and federal emergency management personnel to provide situational awareness so that appropriate emergency-response decisions could be made.

2. Discipline-specific, monitoring channels (e.g. seismic, deformation, gas) provided duty scientists a place for regular updates and discussions related to volcanic processes.

3. The media and public information channel offered a place for questions to be answered from staff involved in the external communication of information with the public.

Internal collaboration tools, like Mattermost, offer valuable and intuitive communications platforms to many organizations. For volcanic crises, especially with noncollocated response staff, such applications create a virtual observatory environment (see Section 6.2). Certainly, it lacks the nuances that accompany in-person communication, but, during an eruption, timely communication is key. Of course, to function well in the field, there needs to be a reliable wireless network and enough equipment to outfit all staff.

\section{Etna, Italy: December 2018: working out external communications roles and protocols}

On the morning of 24 December 2018, approximately $90 \mathrm{~min}$ of energetic seismic activity (volcano-tectonic (VT) earthquakes and tremor) and conspicuous ground deformation preceded the opening of an eruptive fracture of intense lava fountains. After a few hours, the eruption evolved into quiet lava flows in the remote Valle del Bove. The eruption ended in the night between December 26 and 27, but a few hours later, a strong $\left(\mathrm{M}_{\mathrm{L}}=4.8\right)$ earthquake struck the eastern flank of the volcano. This earthquake occurred within an intense seismic swarm that represented the fragile response of the volcanic edifice to the intrusive process (e.g., Bonforte et al. 2019; Giampiccolo et al. 2020).

Although the crisis response by the Operation Room at INGV-OE (Istituto Nazionale di Geofisica e Vulcanologia, Osservatorio Etneo) largely met expectations, two aspects of crisis communications were challenging and deserve highlighting for the volcanological community.

Communications Challenges: The crisis was managed by INGV-OE with Civil Protection authorities according to existing agreements between INGV and the National Department of Civil Protection (INGV 2012). Fortunately, the observatory has had experience with numerous eruptive crises and events over the last 40 years (e.g., The Research Group of the Istituto Nazionale di Geofisica e Vulcanologia-Sezione di Catania, Italy 2001). However, separate official messages by INGV$\mathrm{OE}$ and the INGV National Earthquake Observatory created confusion during the response. That is, separate parts of INGV were responding to the different hazards (earthquake and volcano). Both communication channels were activated after the $\mathrm{M}_{\mathrm{L}}=4.8$ earthquake caused damage to some villages on the eastern side of Mt. Etna: officials at the National Civil Protection Department initially believed that the separate messages implied that the volcanic eruption and the earthquake were not related, creating initial confusion in the activation of the different procedures envisaged to face the two different risks.

A second notable aspect was due to the considerations made by several INGV-OE researchers regarding the nature of the alerts during the unrest phase. During the intense pre-eruption activity $(1.5 \mathrm{~h})$, INGV-OE released three Volcanic Activity Notices containing scientific observations about geology, seismicity, and volcano deformation. According to the existing official agreements, these notices did not need to include forecasts (they are intended to be rapid communications about ongoing phenomena). As a consequence, the potential outcomes of the unrest were not communicated to civil protection authorities. During rapidly changing conditions, the focus of communication is on releasing the latest observed data-it is far more complicated to issue forecasts with appropriate quantified uncertainties. During this crisis, there was some sense that the urgency of information release created conditions where there was delivery of a less-actionable forecast.

Outcomes: The issue of multiple communication channels became the subject of internal discussion at INGV, which led to the adoption of a new communication protocol a few months after the eruption. Beginning in January 2020, it was established that the INGV volcano observatories would be solely responsible for 
communication flow for both volcanic events and earthquakes within volcanic zones. INGV staff are still evaluating how to provide rapid communications that can include useful forecasts. The importance of the topic was recognized by the INGV Volcanoes Department, which recently launched a call for a three-year strategic project. A large group of researchers responded by submitting a proposal for a multidisciplinary research project capable of developing early-warning systems on the basis of the advanced monitoring system, the rich eruptive and geophysical databases, and the most recent analysis methodologies.

\section{Bárðarbunga volcano, Iceland, 2014: an unanticipated gas hazard}

The most recent eruption of Bárðarbunga volcano started on 29 August 2014 and featured lava effusion that originated in the Holuhraun lava field, located about $40 \mathrm{~km}$ NE of the volcano caldera. The eruption lasted 6 months and ended on 27 February 2015 (Pedersen et al. 2017).

The Bárðarbunga volcanic system coincides with the northwest part of the Vatnajökull glacier and is partly covered by ice. Early volcanic unrest in mid-August 2014 consisted of elevated seismicity and a notable deformation field affecting the northwestern part of the glacier and the part of the volcanic system covered by ice. A lateral propagation of the seismicity started after a few days and, together with the deformation rate, revealed a lateral northeasterly path for magma migration (Sigmundsson et al. 2015). The drainage of magma from the reservoir feeding the eruption induced gradual collapse of the caldera (Gudmundsson et al. 2016), which subsided about $60 \mathrm{~m}$. Eventually the eruption took place in the ice-free part of the volcanic system featuring a lava field of $\sim 1.44 \mathrm{~km}^{3}$ (Pedersen et al. 2017) and $\sim 9.2 \mathrm{Mt}$ of $\mathrm{SO}_{2}$ released into the atmosphere (Pfeffer et al. 2018).

The initial hazard evaluation performed at the beginning of unrest by the Scientific Advisory Board anticipated a phreatomagmatic eruption as the most likely scenario with associated tephra fallout and flood hazards. When the eruption took place in an ice-free part of the volcanic system, at a distance of $\sim 70 \mathrm{~km}$ from the closest inhabited area, the scientists thought the impact on society would be minor as no tephra was produced and the lava field covered a very remote region. However, 1 week after the eruption started, air-quality monitoring stations located around the country measured unusually high concentrations of $\mathrm{SO}_{2}$ at ground level (Barsotti et al. 2020; Gíslason et al. 2015). The high concentrations were a serious risk for human health. Very quickly, what was seen as an unlikely scenario became a dangerous nationwide issue that endured for months.
As a result, new mitigation actions had to be rapidly planned, and implemented, including a forecasting system for gas concentrations (Barsotti 2020), deployment of a monitoring network of gas sensors, and restricted access to the eruption site.

The eruption of Bárðarbunga/Holuhraun teaches us at least two important lessons. First, a posteriori analysis suggests that the creation of an event-tree in quiet time between eruptions is highly recommended and, in the Bárðarbunga case, might have encouraged greater preparations for a seemingly unlikely flood basalt scenario. Second, official communications were crafted successfully to provide coherent messages that nonetheless expressed uncertainty. Frequent official communications were provided to the Iceland population by the Civil Protection authorities with input from the scientific community. An official document (factsheet) was disseminated with a unified single-message approach to guarantee integrity of the information and build trust in the responding institutions. Although most messages were developed by consensus, some instances of disagreement occurred. Scientists' uncertainty in interpreting the data and anticipating the potential scenarios was expressed in a transparent way, helping the community to understand and accept the reality that multiple outcomes are possible (and reasonable) in unfolding natural processes like a volcanic eruption.

\section{Cotopaxi, Ecuador 2015: integrating alarms and gaining public trust}

The August 2015- January 2016 eruption of Cotopaxi volcano, Ecuador, was its first eruption in 73 years, notwithstanding several episodes of unrest, including notable ones in 1975 and 2001-2002. The lack of eruptive activity and minimal unrest meant that the public was generally unprepared for an eruption.

Monitoring and Forecasting Successes: Instrumental monitoring on Cotopaxi volcano began in the 1970s (Ramón 1979) and is currently implemented by the Instituto Geofísico of the Escuela Politécnica Nacional (IG-EPN). With nearly 60 permanent instruments, Cotopaxi has a state-of-the-art surveillance system that detected the first signs of unrest in April 2015, 4 months before the first explosions on August 14, 2015 (Hidalgo et al. 2018; Mothes et al. 2019). During the unrest and the ensuing eruption, which lasted until January 24, 2016, IG-EPN was able to apply, test, and modify a suite of different communications practices. For example, weekly forecasts were undertaken by the staff of IG-EPN beginning on May 26, 2015 and included expert elicitation and event trees to inform 
the hazard assessment. The inputs for these exercises were prepared in advance as part of several national ${ }^{1}$ and international projects (BID, SENESCYT, SENPLADES, VUELCO (Ciolli et al. 2014)) and were consolidated at the beginning of the reactivation of Cotopaxi. Additional equipment was added to strengthen the monitoring network, with some assistance from the Volcanic Disaster Assistance Program (VDAP) of the United States Geological Survey (USGS). In partnership with the Ecuadorean Air Force, flights allowed measurements of thermal anomalies and gas composition. Gravimetry campaigns tracked changes in mass distribution within the volcanic edifice. Weekly field missions enabled the staff to keep data flowing from the monitoring network so that gaps in geophysical time series were mostly eliminated. After the eruption started, special reports by IG-EPN were expanded to include dispersion maps of the volcanic cloud and ash fall. The crisis also provided an opportunity to revise the Cotopaxi volcano hazard map with a new version, published in June 2016 (Mothes et al. 2016a, 2016b; Vásconez et al. 2017), which fixed problems in zone boundary accuracy due to map scale inherent to the previous version. A digital story map version of the hazard map was also released on the IG-EPN website in 2020 (https://www.igepn.edu.ec/mapas/peligro-volca nico/mapa-volcan-cotopaxi).

Communications: Prior to the 2015 unrest and eruption, communication on the activity of Cotopaxi volcano was carried out through weekly reports, based primarily on seismic activity, and monthly reports that also included deformation and gas emission. Though these reports were typically read by only a few people, after the initial public reports on May 28 and June 2, there was a ten- to 100-fold increase in the internet audience. Daily reports and special reports with potential eruptive scenarios were published on the IG-EPN web page and social networks. In anticipation of the eruption, IGEPN staff gave numerous lectures to authorities and the public, trying to introduce and explain the hazard map to vulnerable populations. However, some rural communities did not get the information and were caught off guard by the first ash fall resulting in serious loss of livelihoods-particularly in loss of crops and livestock.

Challenges to a Successful Response and Resulting Changes: Although the IG-EPN monitoring protocols were quite robust at the time of the eruption, during the night of August 13-14, the IG-EPN failed to report the beginning of the eruption in a timely fashion.

\footnotetext{
${ }^{1}$ BID $=$ Banco Internacional para el Desarrollo; SENESCYT = Secretaría de Educación Superior, Ciencia, Tecnología e Innovación; SENPLADES = Secretaría Nacional de Planificación y Desarrollo.
}

Unfortunately, the late reporting was used by outside individuals to discredit the work of the IG-EPN, causing confusion and mistrust of the institution. Since then, increased training and use of automated alarms have been implemented to avoid similar problems and the new IGAlInstante format allows monitoring staff to communicate more effectively. Since the 2015 eruption, the IG-EPN has been involved in various outreach projects (DIPECHO, FbF) to increase awareness of volcano information in vulnerable rural communities and to facilitate preparation of response plans.

\section{Nyiragongo volcano, Democratic Republic of the Congo: partnerships with international data consortia improve readiness for a repeat of the 2002 eruption in Goma}

Nyiragongo ( $3470 \mathrm{~m}$ asl) is a highly active volcano located in the western branch of the East African Rift System, in the Democratic Republic of the Congo (DRC) near the border with Rwanda. Nyiragongo is well-known for its large and long-lasting active lava lake and has been very active since May 2002 (Balagizi et al. 2016). During its eruption in January 2002, Nyiragongo produced lava flows that invaded the city of Goma and destroyed its economic district: the most destructive known lava-flow inundation of an urban area (Allard et al. 2003; Komorowski et al. 2003). The eruption destroyed the houses of $\sim 120,000$ people, killed $\sim 140$ people (Baxter and Ancia 2002; Komorowski et al. 2003) and caused an abrupt mass selfevacuation of $\sim 300,000$ people. Presently, Nyiragongo volcano threatens $\sim 1.5$ million inhabitants of the cities of Goma (DRC) and Gisenyi (Rwanda) and people living in the surrounding villages. In November 2017 the Committee for Earth Observation Satellites (CEOS) Plenary 31 approved the establishment of a permanent Supersite in the Virunga volcanic region and Lake Kivu basin (http://geo-gsnl.org/supersites/permanent-supersites/ virunga-supersite/). One of the main goals of the Virunga Volcanoes Supersite is to support, through an open science approach, the improvement of the early warning capacity of the local scientists and agencies involved in geohazards assessment and forecast for volcanic crises in Goma. The supersite has allowed continuous acquisition, free of charge, of a variety of data; e.g. COSMO-SkyMed SAR and Pleiades images, to support both the study and monitoring of Nyiragongo and Nyamulagira volcanoes in order to better understand their eruptive mechanism, and hence better assess the related hazards and manage the risks (Balagizi et al. 2020). An example was a 2018 activation of the Copernicus Emergency Management Service that enabled creation of databases for land use, population, and infrastructure, as well as a very high-resolution digital elevation model (DEM) that served as the basis for simulation of lava flow pathways (Fig. 8). 


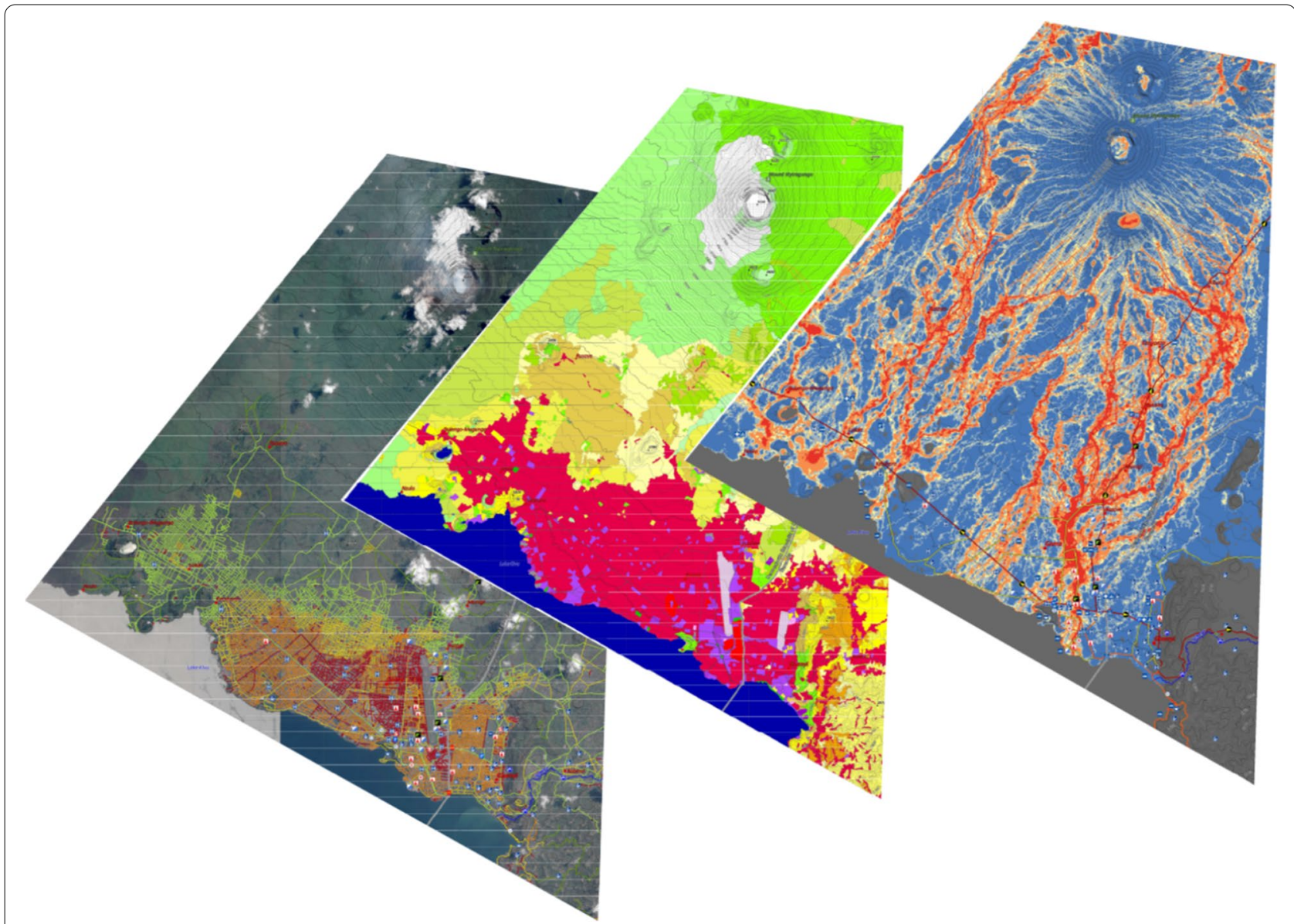

Fig. 8 Maps of land use and cover for Nyiragongo Volcano and the city of Goma developed by the Copernicus - Emergency Management Service Risk and Recovery Mapping and published in Balagizi et al. (2020). They include urban infrastructure (left), land use (center), and lava flow inundation hazards (right). Single, high-resolution maps are available at https://emergency.copernicus.eu/mapping/list-of-components/EMSN047

Creation of the supersite proved prescient when the volcano erupted on 22 May 2021. Through the Supersite, various data sources were available to create InSAR images that revealed migration of a dike during and after the eruption that started at the Nyiragongo summit and extended to the south and underneath the City of Goma. The open science approach coordinated by the GEOGSNL (https://geo-gsnl.org) initiative allowed for rapid sharing of scientific products with decision makers.

\section{Conclusions}

In this document, we have discussed some of the many practices that can aid in preparing volcano observatories for the intense logistics, complex work environment, and stress that accompanies volcanic activity. In addition, six case studies provide insight to recent lessons learned by our colleagues around the world.

Key recommendations are to: 1) organize the data and tools needed to assess volcanic activity and forecast potential outcomes before a crisis occurs; 2) create templates, protocols, staffing plans and checklists that can be used to simplify operations and avoid overlooking key activities; 3 ) work with partners to define roles, responsibilities and shared processes; 4) use exercises to practice key aspects of observatory crisis response; and 5) write response and communication plans that allow the observatory to work efficiently with those authorities managing civil protection.

We recognize that conditions change rapidly and the tools we use, our scientific understanding, and societal norms do not stay fixed. The social networks and technologies discussed herein may not exist in 10 or 20 years, and the ability of volcano observatories to interact, share resources, and learn from our collective history may have undergone considerable alterations. Nevertheless, we anticipate that the need for planning and close partnerships is unlikely to waver even centuries from now. With that in mind, we hope that some of the ideas offered here can provide useful insights for volcanologists in the years to come. 


\section{Supplementary Information}

The online version contains supplementary material available at https://doi. org/10.1186/s13617-021-00112-9.

Additional file 1. Spanish-language translation of this manuscript and its figure captions.

Additional file 2. Tools developed in volcanology for use in eruption response-a list developed by the participants of the VOBP4 workshop.

Additional file 3. References cited in Additional file 2.

Additional file 4. Ash3D Ash Cloud \& Ashfall Model Output Duty Checklists During Unrest.

Additional file 5. AVO Duty Alarms Checklist.

Additional file 6. AVO Duty Remote Sensing Checklist.

Additional file 7. AVO Duty Scientist Checklist.

Additional file 8. AVO Duty Seismologist Checklist.

Additional file 9. AVO Template for Volcano Eruption Chronology.

Additional file 10. Chronology for 2008-09 eruption of Redoubt volcano.

Additional file 11. List of Duties for AVO Response Coordination Team.

Additional file 12. Post-eruption Assessment for Holuhraun.

\section{Acknowledgements}

John Pallister, Ramon Espinasa, Jeff Marso and Paolo Papale undertook much of the logistical and organizational tasks associated with the VOBP meeting in 2019. Pallister and Heather Wright reviewed the manuscript prior to submission to the journal, and John Ewert provided input for several sections. VOBP meeting attendees had the opportunity to read and review the manuscript and Costanza Bonadonna provided many helpful comments. Two very detailed and thoughtful journal reviews provided the impetus to re-organize and refresh the manuscript. We thank Pablo Samaniego, Ramón Espinasa, Jorge Concha, and Luisa Macedo for correcting the initial Spanish translation of Additional file 1. Any use of trade, product, or firm names is for descriptive purposes only and does not imply endorsement by the U.S. Government.

\section{Authors' contributions}

All authors contributed to the preparation and drafting of various parts of the manuscript largely based on rapporteur notes collected during the meeting. With respect to the case studies, 8.1 was written by EG and NF; 8.2 by WS; 8.3 by EP; 8.4 by $S B ; 8.5$ by BB; and 8.6 by CB. JBL was responsible for the final compilation, including the contributions, suggestions, and reviews of the other coauthors and VOBP attendees. KW assembled all the materials in the Additional Files, except for the Holuhraun document (Additional file 12) provided by SB. All authors read and approved the final manuscript. JBL, KW, and WS are funded by the USGS Volcano Hazards Program; JL receives additional funding through the USAID Interagency Agreement that funds VDAP. LS was funded by EUROVOLC project, under the EU Horizon 2020 Research and Innovation Action, grant No. 73107.

\section{Authors' information}

(Not included)

\section{Funding}

Funding for the VOBP4 meeting was provided by the Istituto Nazionale di Geofisica e Vulcanologia, and a United States Agency for International Development (USAID) interagency agreement that funds VDAP at the USGS. Important in-kind contributions were provided by CENAPRED. JBL, KW, and WS receive salary support from the USGS Volcano Hazards Program. JBL receives additional salary support from an interagency agreement from USAID. Several authors received funds from the European Union's Horizon 2020 research and innovation program under the EUROVOLC project under grant agreement No 731070. The funds were available to to SB (through Iceland), to LS (Italy) and to JCK (through France IPGP and CNRS). JCK was further supported by the Institut National des Sciences de I'Univers (INSU-CNRS) and the Service National d'observation en volcanology (SNOV, CNRS-INSU). This study contributes to the IdEx Université de Paris ANR-18-IDEX-0001.

\section{Availability of data and materials}

Information and data used in this manuscript are available in cited papers and observatory records. Rapporteur notes from the meeting and breakout sessions of the VOBP 4 workshop are available from the first author on request.

\section{Declarations}

Ethics approval and consent to participate

Not applicable.

\section{Consent for publication}

Not applicable.

\section{Competing interests}

The authors declare that they have no competing interests.

\section{Author details}

${ }^{1}$ U.S. Geological Survey, Volcano Science Center, Vancouver, WA, USA. ${ }^{2}$ U.S. Geological Survey, Volcano Science Center, AK, Anchorage, USA. ${ }^{3}$ Icelandic Met Office, Reykjavík, Iceland. ${ }^{4}$ Istituto Nazionale di Geofisica e Vulcanologia, Bologna, Italy. ${ }^{5}$ nstituto Geofísico, Escuela Politécnica Nacional, Quito, Ecuador. ${ }^{6}$ Istituto Nazionale di Geofisica e Vulcanologia, Catania, Italy. ${ }^{7}$ Université de Paris, Institut de Physique du Globe de Paris, CNRS, Paris, France. ${ }^{8} \mathrm{GNS}$ Science, Taupō, New Zealand. ${ }^{9}$ Goma Volcano Observatory, Goma, Democratic Republic of the Congo. ${ }^{10}$ Vanuatu Meteorology and Geo-Hazards Department, Port Vila, Vanuatu.

Received: 22 December 2020 Accepted: 21 November 2021

Published online: 14 January 2022

\section{References}

Alaska Volcano Observatory, National Weather Service, Federal Aviation Administration (2017) Department of Defense, United States Coast Guard, Division of Homeland Security and Emergency Management, Alaska Department of Environmental Conservation, and Alaska Department of Health and Social Services (participating agencies). Alaska interagency operating plan for volcanic ash episodes, p 81 https://avo. alaska.edu/pdfs/cit3996_2017.pdf

Allard P, Baxter P, Halbwachs M, Kasereka M, Komorowski JC, Joron JL (2003) The most destructive effusive eruption in modern history: Nyiragongo (RD Congo), January 2002. European geophysical society, XXXVIII general assembly, Nice, France, April 2003. Geophys Res Abst 5:11970

Andreastuti S, Subandriyo J, Sumarti S, Sayudi D (2015) The importance of communication in hazard zone areas: case study during and after 2010 Merapi eruption, Indonesia. In: Loughlin SC, Sparks RSJ, Brown SF, Jenkins SF, Vye-Brown C (eds) Global volcanic hazards and risk. Cambridge University Press, Cambridge, pp 267-271. https://doi.org/10.1017/ CBO9781316276273.012

Annelli JF (2006) The national incident management system: a multi-agency approach to emergency response in the United States of America. Rev Sci Tech 25(1):223-231

Asgary A, Bonadonna C, Frischknecht C (2020) Simulation and visualization of Volcanic phenomena using Microsoft Hololens: case of Vulcano Island (Italy). IEEE Trans Eng Manag 67(3):545-553. https://doi.org/10.1109/ TEM.2019.2932291

Aspinall W, Cooke RM (1998) Expert judgement and the Montserrat volcano eruption. In: Mosleh A (ed) Proceedings of the 4th international conference on probabilistic safety assessment and management. Springer, London, PSAM4 3, pp 13-18

Balagizi MC, Mavonga G, Kasereka MM, Liotta M, Manzo M, Lanari R, Bonano M, De Luca C, Onorato G, Lukindula J, Ganci G, Del Negro C, Cappello A, Coltelli M, Mattia M, Coppola D, Durrheim RJ, Mukambilwa P, Kyambikwa A, Mashagiro N, Ciraba H, Lowenstern JB, Kelly PJ, McCausland WA, Kies A (2020) Virunga Volcanoes Supersite Biennial Report: 2017-2019. https://doi.org/10.5281/zenodo.3911065

Balagizi MC, Yalire MM, Ciraba MH, Vicky BK, Minani SA, Kinja KA, Kasereka $\mathrm{MM}$ (2016) $\mathrm{CO}_{2}$ and $\mathrm{SO}_{2}$ emissions, temperature variations and field observations before and after the February 29, 2016 new vent inside 
Nyiragongo crater. Bull Volcanol 78:64. https://doi.org/10.1007/ s00445-016-1055-y

Barberi F, Zuccaro G (2004) SOMMA VESUVIUS MESIMEX, Final Technical Implementation Report. https://ec.europa.eu/echo/files/civil_protection/ civil/prote/pdfdocs/mesimex.pdf. Accessed 25 Nov 2020

Barsotti S (2020) Probabilistic hazard maps for operational use: the case of SO2 air pollution during the Holuhraun eruption (Bárðarbunga, Iceland) in 2014-2015. Bull Volcanol 82(56)

Barsotti S, Di Rienzo DI, Thordarson T, Björnsson BB, Karlsdóttir S (2018) Assessing impact to infrastructures due to tephra fallout from Öræfajökull volcano (Iceland) by using a scenario-based approach and a numerical model. Front Earth Sci 6:196. https://doi.org/10.3389/ feart.2018.00196

Barsotti S, Oddsson B, Gudmundsson MT, Pfeffer MA, Parks MM, Ófeigsson BG, Sigmundsson F, Reynisson V, Jónsdóttir K, Roberts MJ, Heiðarsson EP, Jónasdóttir EB, Einarsson P, Jóhannsson T, Gylfason ÁG, Vogfjörd $K$ (2020) Operational response and hazards assessment during the 2014-2015 volcanic crisis at Bárðarbunga volcano and associated eruption at Holuhraun. Iceland J Volcanol Geotherm Res 390:106753. https://doi.org/10.1016/j.jvolgeores.2019.106753

Bartel B, Bohon W, Frank L, Stovall W, Poland M (2020). Communicating Geohazard: delivering information in crisis and calm. Unavco, p 31. https:// www.unavco.org/about/organization/education-and-communityengagement/publications-internal-reports-and-white-papers/Commu nicatingGeohazards2019Handbook.pdf. Accessed 25 Nov 2020

Baxter P, Ancia A (2002) Human health and vulnerability in the Nyiragongo volcano eruption and humanitarian crisis at Goma, Democratic Republic of Congo, final report to the World Health Organization. https://relie fweb.int/report/democratic-republic-congo/human-health-and-vulne rability-nyiragongo-volcano-crisis-dr-congo. Accessed 25 Nov 2020

Beauducel F, Lafon D, Béguin X, Saurel J-M, Bosson A, Mallarino D, Boissier P, Brunet C, Lemarchand A, Anténor-Habazac C, Nercessian A, Fahmi AA (2020) WebObs: the volcano observatories missing link between research and real-time monitoring. Front. Earth Sci 8(48). https://doi. org/10.3389/feart.2020.00048

Bernard B (2013) Homemade ashmeter: a low-cost, high-efficiency solution to improve tephra field-data collection for contemporary explosive eruptions. J Appl Volc 2:1. https://doi.org/10.1186/2191-5040-2-1

Bernard B, Stock MJ, Coppola D, Hidalgo S, Bagnardi M, Gibson S, Hernandez S, Ramón P, Gleeson M (2019) Chronology and phenomenology of the 1982 and 2015 wolf volcano eruptions, Galápagos archipelago. J Volcanol Geotherm Res 374:26-38. https://doi.org/10.1016/j.jvolgeores. 2019.02.013

Bonadonna C (2006) Probabilistic modelling of tephra dispersion. In: Mader HM, Coles SG, Connor CB, Connor LJ (eds) Statistics in volcanology. Spec Public IAVCEl; 1. Geol Soc, London, pp 243-259

Bonforte A, Guglielmino F, Puglisi G (2019) Large dyke intrusion and small eruption: the December 24, $2018 \mathrm{Mt}$. Etna eruption imaged by Sentinel-1 data. Terra Nova 31:405-412. https://doi.org/10.1111/ter.12403

Bretton RJ, Ciolli S, Cristiani C, Gottsmann J, Christie R, Aspinall W (2018) Volcanic unrest simulation exercises: Checklists and guidance notes. In: Gottsmann J, Neuberg J, Scheu B (eds) Volcanic Unrest. Advances in Volcanology. Springer, pp 271-298. https://doi.org/10.1007/11157 2018_34

Calder E, Wagner K, Ogburn S (2015) Volcanic hazard maps. In:Volcanic G (ed) S Loughlin, S Sparks, S Brown, S Jenkins C Vye-Brown. Cambridge University Press, Hazards and Risk, pp 335-342

Camejo M, Robertson R (2013) Estimating volcanic risk in the Lesser Antilles: Univ West Indies seismic res Centre, SRC open-file report 2013-1001 p 49. Available on Vhub. https://vhub.org/resources/2910/download/ RiskReport.pdf. Accessed on 25 Nov 2020

Carn SA, Pallister JS, Lara L, Ewert JW, Watt S, Prata AJ, Thomas RJ, Villarosa G (2009) The unexpected awakening of Chaitén volcano, Chile. EOS Trans Am Geophys Union 90:205-206

Ciolli S, Andrade D, Ruiz M, Cristiani C (2014) VUELCO-Cotopaxi Volcano Exercise- Debriefing. Report.:9. https://doi.org/10.13140/RG.2.2.29651.58406

Coombs ML, Wech AG, Haney MM, Lyons JJ, Schneider DJ, Schwaiger HF, Wallace KL, Fee D, Freymueller JT (2018) Schaefer JR and Tepp G (2018) short-term forecasting and detection of explosions during the 2016-2017 eruption of Bogoslof volcano, Alaska. Front Earth Sci 6:122. https://doi.org/10.3389/feart.2018.00122
Costa F, Widiwijayanti C, Humaida H (2019) Data from past eruptions could reduce future volcano hazards. Eos 100. https://doi.org/10.1029/2019E 0118941

Crosweller HS, Arora B, Brown SK et al (2012) Global database on large magnitude explosive volcanic eruptions (LaMEVE). J Appl Volcanol 1:4. https:// doi.org/10.1186/2191-5040-1-4

Doyle EEH, Paton D, Johnston DM (2015) Enhancing scientific response in a crisis: evidence based approaches from emergency management in New Zealand. J Appl Volcanol 4(1):26. https://doi.org/10.1186/ s13617-014-0020-8

Driedger C, Neal CA, Knappenberger TH, Needham DH, Harper RB, Steele WP (2008) Hazard information management during the autumn 2004 reawakening of Mount St. Helens Volcano, Washington. In: Sherrod DR, Scott WE, Stauffer PH (eds) A volcano rekindled: the renewed eruption of Mount St. Helens, U.S. Geol Surv Prof Paper 1750, https://pubs.usgs. gov/pp/1750/, pp 505-519

Esposti Ongaro T, Neri A, Menconi G, de'Michieli Vitturi M, Marianelli M, Cavazzoni C, Erbacci G, Baxter PJ (2008) Transient 3D numerical simulations of column collapse and pyroclastic density current scenarios at Vesuvius. J Volcanol Geotherm Res 178:378-396

Ewert JW, Diefenbach AK, Ramsey DW (2018) Update to the U.S. Geological Survey national volcanic threat assessment. U.S. Geol Surv Sci Invest Report 2018-5140, p 40. https://doi.org/10.3133/sir20185140

Ewert JW, Guffanti M, Murray TL (2005) An assessment of volcanic threat and monitoring capabilities in the United States-Framework for a National Volcano Early Warning System. U.S. Geol Surv Open-File Report 2005-1164, p 62

Fearnley C (2013) Assigning a volcano alert level: negotiating uncertainty, risk, and complexity in decision-making processes. Environ Plan 45:1891-1911

Fearnley C, Winson AEG, Pallister J, Tilling R (2017) Volcano crisis communication: challenges and solutions in the twenty-first century. In: Fearnley CJ, Bird DK, Haynes K, WJ MG, Jolly G (eds) Observing the volcano world; advances in volcanology (an official book series of the International Association of Volcanology and Chemistry of the Earth's interior - IAVCEI, Barcelona, Spain). Springer, Cham. https://doi.org/10.1007/ 11157_2017_28

Fee D, Lyons J, Haney M, Wech A, Waythomas C, Diefenbach AL, Lopez T, Van Eaton A, Schneider D (2020) Seismo-acoustic evidence for vent drying during shallow submarine eruptions at Bogoslof volcano, Alaska. Bull Volcanol 82(1):2. https://doi.org/10.1007/s00445-019-1326-5

FEMA (2017) (2017) National Incident Management System, 3rd Edition, p 123 https://www.fema.gov/sites/default/files/2020-07/fema_nims_doctr ine-2017.pdf

Fiske RS (1984) Volcanologists, journalists, and the concerned public: a tale of two crises in the eastern Caribbean, in explosive volcanism: inception, evolution, and hazards. National Academy Press, Washington, D.C, pp 170-176

Francis P, Rothery D (2000) Remote sensing of active volcanoes. Annu Rev Earth Planet Sci 28(1). https://doi.org/10.1146/annurev.earth.28.1.81

Galle B, Johansson M, Rivera C, Zhang Y, Kihlman M, Kern C, Lehmann T, Platt U, Arellano S, Hildago S (2010) Network for observation of volcanic and atmospheric change (NOVAC) -- a global network for volcanic gas monitoring: network layout and instrument description. J Geophys Res, Atm 115(D5). https://doi.org/10.1029/2009JD011823

Giampiccolo E, Cocina O, De Gor P et al (2020) Dyke intrusion and stressinduced collapse of volcano flanks: the example of the 2018 event at Mt. Etna (Sicily, Italy). Sci Rep 10:6373. https://doi.org/10.1038/ s41598-020-63371-3

Gíslason SR, Stefánsdóttir G, Pfeffer MA, Barsotti S, Jóhannsson T, Galeczka I, Bali E, Sigmarsson O, Stefánsson A, Keller NS, Sigurdsson Á, Bergsson B, Galle B, Jacobo VC, Arellano S, Aiuppa A, Jónasdóttir EB, Eiríksdóttir ES, Jakobsson S, Gudmundsson MT (2015) Environmental pressure from the 2014-15 eruption of Bárðarbunga volcano, Iceland. Geochem Perspectives Lett 1(0):84-93. https://doi.org/10.7185/geochemlet.1509

Global Volcanism Program. Volcanoes of the World, v. 4.9 .0 (2013) (04 Jun 2020). Venzke, E (ed.). Smithsonian Institution. https://doi.org/10.5479/ si.GVP.VOTW4-2013

Gudmundsson MT, Jónsdóttir K, Hooper A, Holohan EP, Halldórsson SA, Ófeigsson BG, Cesca S, Vogfjörd KS, Sigmundsson F, Högnadóttir T (2016) Gradual caldera collapse at Bárdarbunga volcano, Iceland, regulated by 
lateral magma outflow. Science 353(6296):aaf8988. https://doi.org/10. 1126/science.aaf8988

Hall M, Ramón P, Mothes P, LePennec J, García A, Sanmiego P, Yepes H (2004) Volcanic eruptions with little warning: the case of Volcán Reventador's surprise November 3, 2002 eruption. Ecuador Revista Geológica Chile 31(2):349-358

Harnett CE, Thomas ME, Calder ES et al (2019) Presentation and analysis of a worldwide database for lava dome collapse events: the global archive of dome instabilities (GLADIS). Bull Volcanol 81:16. https://doi.org/10. 1007/s00445-019-1276-y

Hidalgo S, Battaglia J, Arellano S, Sierra D, Bernard B, Parra R, Kelly P, Dinger F, Barrington C, Samaniego P (2018) Evolution of the 2015 Cotopaxi eruption revealed by combined geochemical and seismic observations. Geochem Geophys Geosys 19:2087-2108. https://doi.org/10.1029/ 2018GC007514

IAVCEI Subcommittee for Crisis Protocols (Newhall C, Aramaki S, Barberi F, Blong R, Calvache M, Cheminee J-L, Punongbayan R, Siebe C, Simkin T, Sparks RSJ, Tjetjep W) (1999). Professional conduct of scientists during volcanic crises. Bull Volcanol 60:323-334

IAVCEI Task Group on Crisis Protocols (Giordano G, Bretton R, Calder E, Cas R, Gottsmann J, Lindsay J, Newhall C, Pallister J, Papale P, Rodriguez L) (2016) Toward IAVCEI guidelines on the roles and responsibilities of scientists involved in volcanic hazard evaluation, risk mitigation, and crisis response. Bull Volcanol 78(31):3. https://doi.org/10.1007/ s00445-016-1021-8

INGV (2012). Annex A to the Framework Agreement between the Department of Civil Protection and the National Institute of Geophysics and Volcanology for seismic and volcanic surveillance on the national territory, technical-scientific advice and studies on seismic and volcanic risks (decade 2012-2021). In Italian. http://istituto.ingv.it/l-ingv/proge tti/allegati-convenzioni-dpc/allegati-convenzione-quadro-2012-2021/ accordo-quadro-2012-2021-allegato\%20A.pdf. Accessed 25 Nov 2020

Iverson RM, Schilling SP, Vallance JW (1998) Objective delineation of laharinundation hazard zones. Geol Soc Am Bull 110(8):972-984

Kelfoun K, Samaniego P, Palacios P, Barba D (2009) Testing the suitability of frictional behaviour for pyroclastic flow simulation by comparison with a well-constrained eruption at Tungurahua volcano (Ecuador). Bull Volcanol 71:1057-1075. https://doi.org/10.1007/s00445-009-0286-6

Komorowski JC, Tedesco D, Kasereka MC, Allard P, Papale P, Vaselli O, Durieux J et al (2003) The January 2002 flank eruption of Nyiragongo volcano (Democratic Republic of Congo): chronology, evidence for a tectonic rift trigger, and impact of lava flows on the city of Goma. Acta Vulcanol 15(1-2):27-62

Lara LE, Clavero J, Hinojosa M, Huerta S, Wall R, Moreno H (2006) NVEWSChile-Sistema de clasifcación semicuantitativa de la vulnerabilidad volcánica: Congreso Geológico Chileno. Antofagasta, Chile 11(2):487-490

Leonard GS, Johnson DM, Paton D, Christianson A, Becker J, Keys H (2008) Developing effective warning systems: ongoing research at Ruapehu volcano, New Zealand. J Volc Geothermal Res 172(3-4):199-215. https://doi.org/10.1016/j.jvolgeores.2007.12.008

Lowenstern JB, Ramsey DW (2017) The Volcano Disaster Assistance ProgramHelping to save lives worldwide for more than 30 years. U.S. Geol Surv:2017-30716. https://doi.org/10.3133/fs20173071

Marti J, Aspinall W, Sobradelo R, Felpeto A, Geyer A, Ortiz R, Baxter P, Cole P, Pacheco J, Blanco MJ (2008) Lopez C (2008) a long-term volcanic hazard event tree for Teide-Pico Viejo stratovolcanoes (Tenerife, Canary Islands). J Volcanol Geotherm Res 178:543-552. https://doi.org/10.1016/j.jvolg eores.2008.09.023

Marzocchi W, Sandri L, Selva J (2008) BET_EF: a probabilistic tool for long- and short-term eruption forecasting. Bull Volcanol 70:623-632. https://doi. org/10.1007/s00445-007-0157-y

Marzocchi W, Sandri L, Selva J (2010) BET_VH: a probabilistic tool for long-term volcanic hazard assessment. Bull Volcanol 72:705-16. https://doi.org/10. 1007/s00445-010-0357-8

Marzocchi W, Sandri L, Gasparini P, Newhall CG, Boschi E (2004) Quantifying probabilities of volcanic events: the example of volcanic hazard at Mount Vesuvius. J Geophys Res:109-B11201. https://doi.org/10.1029/ 2004JB003155

Mastin LG, Guffanti M, Servranckx R, Webley P, Barsotti S, Dean K, Durant A, Ewert JW, Neri A, Rose WI, Schneider D (2009) A multidisciplinary effort to assign realistic source parameters to models of volcanic ash-cloud transport and dispersion during eruptions. J Volcanol Geotherm Res 186(1-2):10-21. https://doi.org/10.1016/j.jvolgeores.2009.01.008

McCausland WA, Pallister JS, Andreastutti S, Gunawan H, Hendrasto M, Kasbani, Iguchi M, Nakada S (eds special issue 2019) Lessons learned from the recent eruptions of Sinabung and Kelud volcanoes, Indonesia. J Volc Geotherm Res 382: 1-310

Miller CA (2010) Threat assessment of New Zealand's volcanoes and their current and future monitoring requirements Lower Hutt, N.Z: GNS science. GNS Sci Rep 2011(55):45 http://shop.gns.cri.nz/sr_2010-055-pdf/

Miller CA, Jolly AD (2014) A model for developing best practice volcano monitoring: a combined threat assessment, consultation and network effectiveness approach. Nat Hazards 71:493-522. https://doi.org/10. 1007/s11069-013-0928-z

Ministry of Civil Defence and Emergency Management (2008) Exercise Ruaumoko 08, Final Exercise Report. https://dpmc.govt.nz/sites/default/files/ 2019-11/dpmc-roiar-oia-2019-20-0222-exercise-ruaumoko-final-report. pdf

Moran SC, Freymueller JT, LaHusen RG, McGee KA, Poland MP, Power JA, Schmidt DA, Schneider DJ, Stephens G, Werner CA, White RA (2008) Instrumentation recommendations for volcano monitoring at U.S. volcanoes under the National Volcano Early Warning System: U.S. Geol Surv Sci Investig Rep 2008:5114 47

Mothes P, Espín P, Hall ML, Vásconez F, Sierra D, Andrade D (2016b) Mapa Regional de Amenazas Volcánicas Potenciales del Volcán Cotopaxi Zona Norte 2016. https://doi.org/10.13140/RG.2.2.21035.03363

Mothes P, Espín P, Hall ML, Vásconez F, Sierra D, Córdova M, Santamaría S (2016a) Mapa Regional de Amenazas Volcánicas Potenciales del Volcán Cotopaxi - Zona Sur. https://doi.org/10.13140/RG.2.2.24498.61129

Mothes PA, Ruiz MC, Viracucha EG, Ramón PA, Hernández S, Hidalgo S, Bernard B, Gaunt EH, Jarrín P, Yépez MA, Espín PA (2019) Geophysical footprints of Cotopaxi's unrest and minor eruptions in 2015: an opportunity to test scientific and community preparedness. In: Gottsmann J, Neuberg J, Scheu B (eds) Volcanic Unrest : from science to society. Springer International Publishing, Champ, pp 241-270

Muñoz J, Moreno H (2010) From Chaitén to the Chilean volcano monitoring network. AGU Fall Meeting 2010 V21D-2353

Nakada S, Miyagi Y, Kubo T, Fujita E (2019) Conveying volcano information effectively to stakeholders - a new project for promotion of next generation volcano research. J Disaster Res 14(4):623-629

Neal CA et al (2019) The 2018 rift eruption and summit collapse of Kilauea volcano. Science. 363(6425):367-374. https://doi.org/10.1126/science. aav7046

Newhall C, Hoblitt R (2002) Constructing event trees for volcanic crises. Bull Volcanol 64(1):3-20. https://doi.org/10.1007/s004450100173

Newhall C, Pallister JS, Miller CD (2020) A checklist for crisis operations within volcano observatories, Volcanic hazards, risks and disasters. In: Papale P (ed) Forecasting and planning for Volcanic hazards, risks, and disasters, chapter 13. Elsevier, pp 493-544. https://doi.org/10.1016/B978-0-12818082-2.00013-5

Newhall CG, Costa F, Ratdomopurbo A, Venezky DY, Widiwijayanti C, Win NTZ, Tan K, Fajiculay E (2017) WOVOdat — an online, growing library of worldwide volcanic unrest. JVolcanol Geotherm Res 345:184-199. https://doi.org/10. 1016/j.jvolgeores.2017.08.003

Ogburn SE, Loughlin SC, Calder ES (2012) DomeHaz: dome-forming eruptions database v2.4. https://vhub.org/groups/domedatabase

ONEMI (Chile) (2018) Plan específico de emergencia por variable de riesgo: Erupciones Volcánicas, p 46 https://www.onemi.gov.cl/wp-content/uploa ds/2018/09/PEEVR_ERUPCIONES-VOLCÁNICAS_01.02.18.pdf

Orsi G, Di Vito MA, Isaia R (2004) Volcanic hazard assessment at the restless Campi Flegrei caldera. Bull Volcanol 66:514-530. https://doi.org/10.1007/ s00445-003-0336-4

Pallister J, Papale P, Eichelberger J, Newhall C, Mandeville C, Nakada S, Marzocchi W, Loughlin S, Jolly G, Ewert J, Selva J (2019) Volcano observatory best practices (VOBP) workshops - a summary of findings and best-practice recommendations. J App Volcanol 8(2):33. https://doi.org/10.1186/ s13617-019-0082-8

Papale P (2017) Rational volcanic hazard forecasts and the use of volcanic alert levels. J Appl Volcanol 6:13. https://doi.org/10.1186/s13617-017-0064-7 Pedersen G, Höskuldsson A, Dürig T, Thordarson T, Jonsdottir I, Riishuus MS, Óskarsson BV, Dumont S, Magnússon E, Gudmundsson MT (2017) Lava 
field evolution and emplacement dynamics of the 2014-2015 basaltic fissure eruption at Holuhraun, Iceland. J Volcanol Geotherm Res 340:155169. https://doi.org/10.1016/j.jvolgeores.2017.02.027

Perry RW (2003) Incident management systems in disaster management. Disaster Prev Manag 12(5):405-412. https://doi.org/10.1 108/09653560310507226

Pfeffer M, Bergsson B, Barsotti S, Stefánsdóttir G, Galle B, Arellano S, Conde V, Donovan A, llyinskaya E, Burton M (2018) Ground-based measurements of the 2014-2015 Holuhraun Volcanic cloud (Iceland). Geosciences 8(1):29. https://doi.org/10.3390/geosciences8010029

Pierson TC, Driedger CL, Tilling RI (2013) Volcano crisis response at Yellowstone volcanic complex - after-action report for exercise held at Salt Lake City, Utah, November 15, 2011: U.S. Geol Surv Open-File Report 2013-1018, p 31 http://pubs.usgs.gov/of/2013/1018/

Poland MP, Lopez T, Wright R et al (2020) Forecasting, detecting, and tracking Volcanic eruptions from space. Remote Sens Earth Syst Sci 3:55-94. https:// doi.org/10.1007/s41976-020-00034-x

Potter SH, Scott BJ, Fearnley CJ, Leonard GS, Gregg CE (2017) Challenges and benefits of Standardising early warning systems: a case study of New Zealand's Volcanic alert level system. In: Fearnley CJ, Bird DK, Haynes K, McGuire WJ, Jolly G (eds) Observing the volcano world. Advances in Volcanology (An Official Book Series of the International Association of Volcanology and Chemistry of the Earth's Interior - IAVCEI, Barcelona, Spain). Springer, Cham. https://doi.org/10.1007/11157_2017_18

Ramón P (1979) Tecnología y aplicación de instrumentos geofísicos en el volcanismo, ensayos en el volcán Cotopaxi. Graduate thesis, EPN, Quito-Ecuador, p 97

Re CRA, D'Oriano C, Pompilio M (2021) Petrological monitoring of active volcanoes: a review of existing procedures to achieve best practices and operative protocols during eruptions. JVolc Geotherm Res 419:107365. https://doi.org/10.1016/j.jvolgeores.2021.107365

Reath K, Pritchard M, Poland M et al (2019) Thermal, deformation, and degassing remote sensing time series (CE 2000-2017) at the 47 most active volcanoes in Latin America: implications for Volcanic systems. J Geophys Res Solid Earth. https://doi.org/10.1029/2018JB016199

Sandri L, Costa A, Selva J, Tonini R, Macedonio G, Folch A, Sulpizio R (2016) Beyond eruptive scenarios: assessing tephra fallout hazard from Neapolitan volcanoes. Sci Rep 6:24271. https://doi.org/10.1038/srep24271

Sandri L, Jolly G, Lindsay J, Howe T, Marzocchi W (2012) Combining long- and short-term probabilistic volcanic hazard assessment with cost-benefit analysis to support decision making in a volcanic crisis from the Auckland Volcanic field, New Zealand. Bull Volcanol 74:705-723. https://doi.org/10. 1007/s00445-011-0556-y

Sarsito DA, Kriswati E, Meilano I, Andreas H, Pradipta D (2019) Volcano deformation monitoring using geodetic method: optimal network design. IOP Con Ser: Earth Enviro Sci 389:012039

Sennert SSK, Klemetti EW, Bird DK (2015) Role of social media and networking in volcanic crises and communication. In: Fearnley $C J$, Bird DK, Haynes K, McGuire WJ, Jolly G (eds) Observing the volcano world; advances in volcanology (an official book series of the International Association of Volcanology and Chemistry of the Earth's interior - IAVCEI, Barcelona). Springer, Cham, pp 733-743. https://doi.org/10.1007/11157_2015_13

Shimano T, Nishimura T, Chiga N, Shibasaki Y, Iguchi M, Miki D, Yokoo A (2013) Development of an automatic volcanic ash sampling apparatus for active volcanoes. Bull Volcanol 75:773. https://doi.org/10.1007/ s00445-013-0773-7

Sigmundsson F, Hooper A, Hreinsdóttir S, Vogfjörd KS, Ófeigsson BG, Heimisson ER, Dumont S, Parks M, Spaans K, Gudmundsson GB (2015) Segmented lateral dyke growth in a rifting event at Bárðarbunga volcanic system. Iceland Nature 517(7533):191-195. https://doi.org/10.1038/nature14111

Sparks RSJ (2003) Forecasting volcanic eruptions. Earth Planet Sci Lett 210(1-2):1-15

Surono et al. (2012) The 2010 explosive eruption of Java's Merapi volcano-a '100-year' event. J Volcanol Geotherm Res 241-241, p 121-135. https://doi. org/10.1016/j.jvolgeores.2012.06.018

Syahbana D et al (2019) The 2017-19 activity at mount Agung in Bali (Indonesia): intense unrest, monitoring, crisis response, evacuation, and eruption. Sci Reports 9:8848. https://doi.org/10.1038/s41598-019-45295-9

Tarquini S, de'Michieli Vitturi M, Jensen E, Pedersen G, Barsotti S, Coppola D, Pfeffer MA (2018) Modeling lava flow propagation over a flat landscape by using MrLavaLoba: the case of the 2014-2015 eruption at Holuhraun, Iceland. Ann Geophys 61:28. https://doi.org/10.4401/ag-7812
The Research Group of the Istituto Nazionale di Geofisica e Vulcanologia-Sezione di Catania, Italy (2001) Multidisciplinary approach yields insight into mt. Etna eruption, Eos trans. AGU 82(52):653-656. https://doi.org/10.1029/ $01 \mathrm{EO} 00376$

Thompson MA, Lindsay JM, Leonard GS (2017) More than meets the eye: Volcanic Hazard map design and visual communication. In: Fearnley CJ, Bird DK, Haynes K, McGuire WJ, Jolly G (eds) Observing the volcano world. Advances in Volcanology (An Official Book Series of the International Association of Volcanology and Chemistry of the Earth's Interior - IAVCEI, Barcelona). Springer, Cham

UNDAC (2018) United Nations disaster assessment coordination (UNDAC) field handbook 7th version 2018; https://www.unocha.org/sites/unocha/files/ 1823826E_web.pdf

UNDRR (2015). The Sendai Framework for Disaster Risk Reduction 2015-2030. 32 pp. http://www.unisdr.org/we/inform/publications/43291

Vásconez F, Sierra D, Almeida M, Andrade D, Marrero JM, Mothes PA, Bernard B, Encalada M (2017) Mapa preliminar de amenazas potenciales del volcán Cotopaxi-Zona oriental. https://doi.org/10.13140/RG.2.2.24418.89280

Venezky DY, Newhall CG (2007) WOVOdat Design Document: The Schema, Table Descriptions, and Create Table Statements for the Database of Worldwide Volcanic Unrest (WOVOdat Version 1.0). US Geol Surv Open-File Rep 2007-1117, p 177

Voight B (1990) The 1985 Nevado del Ruiz volcano catastrophe: anatomy and retrospection. J Volcanol Geotherm Res 42:151-188

(2012) Washington military department emergency management division. Coordinating efforts between governmental agencies in the event of volcanic unrest at mount baker or glacier peak, Washington, p 39 https://volca noes.usgs.gov/vsc/mount_baker_glacier_peak_coordination_plan.pdf

Williams DM, Avery VF, Coombs ML, Cox DA, Horwitz LR, McBride SK, McClymont RJ, Moran SC (2020) U.S. Geological Survey 2018 Killauea Volcano eruption response in Hawai' - - After-action review. U.S. Geol Surv Open-File Report 2020-1041, p 56. https://doi.org/10.3133/ofr20201041

Witham C, Barsotti S, Dumont S, Oddsson B, Sigmundsson F (2020) Practising an explosive eruption in Iceland: outcomes from a European exercise. J Appl Volcanol 9(1):1-16

Wright HNM et al (2019) Construction of probabilistic event trees for eruption forecasting at Sinabung volcano, Indonesia 2013-14. J Volc Geotherm Res 382:233-252

Young SR, Voight B, Sparks RSJ, Rowley K, Robertson REA, Lynch LL, Aspinall WP (1998) The Soufriere Hills eruption, Montserrat, British West Indies: introduction to special section, part 2. Geophys Res Lett 25(19):3651. https://doi.org/10.1029/98GS02437

\section{Publisher's Note}

Springer Nature remains neutral with regard to jurisdictional claims in published maps and institutional affiliations. 